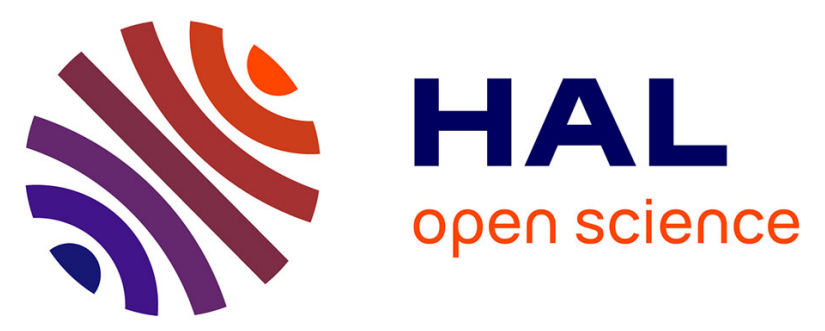

\title{
A G protein-coupled receptor mediates neuropeptide-induced oocyte maturation in the jellyfish Clytia
}

\author{
Gonzalo Quiroga Artigas, Pascal Lapébie, Lucas R Leclère, Philipp \\ Bauknecht, Julie Uveira, Sandra Chevalier, Gáspár Jékely, Tsuyoshi Momose, \\ Evelyn Houliston
}

\section{To cite this version:}

Gonzalo Quiroga Artigas, Pascal Lapébie, Lucas R Leclère, Philipp Bauknecht, Julie Uveira, et al.. A G protein-coupled receptor mediates neuropeptide-induced oocyte maturation in the jellyfish Clytia. PLoS Biology, 2020, 18 (3), pp.e3000614. 10.1371/journal.pbio.3000614 . hal-02569468

\section{HAL Id: hal-02569468 https://hal.science/hal-02569468}

Submitted on 11 May 2020

HAL is a multi-disciplinary open access archive for the deposit and dissemination of scientific research documents, whether they are published or not. The documents may come from teaching and research institutions in France or abroad, or from public or private research centers.
L'archive ouverte pluridisciplinaire HAL, est destinée au dépôt et à la diffusion de documents scientifiques de niveau recherche, publiés ou non, émanant des établissements d'enseignement et de recherche français ou étrangers, des laboratoires publics ou privés. 


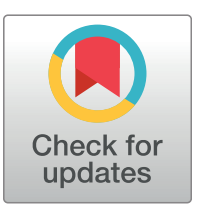

\section{G openaccess}

Citation: Quiroga Artigas G, Lapébie P, Leclère L, Bauknecht P, Uveira J, Chevalier S, et al. (2020) A $G$ protein-coupled receptor mediates neuropeptide-induced oocyte maturation in the jellyfish Clytia. PLoS Biol 18(3): e3000614. https:// doi.org/10.1371/journal.pbio.3000614

Academic Editor: Mariana Federica Wolfner, Cornell University, UNITED STATES

Received: October 15, 2019

Accepted: January 28, 2020

Published: March 3, 2020

Copyright: @ 2020 Quiroga Artigas et al. This is an open access article distributed under the terms of the Creative Commons Attribution License, which permits unrestricted use, distribution, and reproduction in any medium, provided the original author and source are credited.

Data Availability Statement: All sequence files for the GPCRs cloned in this study have been deposited in Genbank. Accession numbers are provided in the Supporting Information file, S2 Text.

Funding: Funding was provided by the EU Marie Curie ITN NEPTUNE (grant agreement: 317172) to EH and GJ, French ANR grant OOCAMP-ANR-13BSV2-0008 to EH, the EU Horizon 2020 programme ASSEMBLE Plus project (grant agreement: 730984) to TM, as well as core funding
RESEARCH ARTICLE

\section{A G protein-coupled receptor mediates neuropeptide-induced oocyte maturation in the jellyfish Clytia}

\author{
Gonzalo Quiroga Artigas ${ }^{11}$, Pascal Lapébie ${ }^{1}$, Lucas Leclère $\oplus^{1}$, Philipp Bauknecht ${ }^{2}$, \\ Julie Uveira ${ }^{1}$, Sandra Chevalier ${ }^{1}$, Gáspár Jékely ${ }^{2,3}$, Tsuyoshi Momose $\oplus^{1}{ }^{1}$, \\ Evelyn Houliston $\mathbb{1}^{1 *}$
}

1 Sorbonne University, CNRS, Villefranche-sur-mer Developmental Biology Laboratory (LBDV), Villefranchesur-mer, France, 2 Max Planck Institute for Developmental Biology, Tübingen, Germany, 3 Living Systems Institute, University of Exeter, Exeter, United Kingdom

a Current address: The Whitney Laboratory for Marine Bioscience, University of Florida, St. Augustine, Florida, United States of America

* houliston@obs-vlfr.fr

\section{Abstract}

The reproductive hormones that trigger oocyte meiotic maturation and release from the ovary vary greatly between animal species. Identification of receptors for these maturation-inducing hormones (MlHs) and understanding how they initiate the largely conserved maturation process remain important challenges. In hydrozoan cnidarians including the jellyfish Clytia hemisphaerica, MIH comprises neuropeptides released from somatic cells of the gonad. We identified the receptor (MIHR) for these MIH neuropeptides in Clytia using cell culture-based "deorphanization" of candidate oocyte-expressed G protein-coupled receptors (GPCRs). MIHR mutant jellyfish generated using CRISPR-Cas9 editing had severe defects in gamete development or in spawning both in males and females. Female gonads, or oocytes isolated from MIHR mutants, failed to respond to synthetic MIH. Treatment with the CAMP analogue $\mathrm{Br}$-cAMP to mimic cAMP rise at maturation onset rescued meiotic maturation and spawning. Injection of inhibitory antibodies to the alpha subunit of the $\mathrm{G}_{\mathrm{s}}$ heterodimeric protein $\left(G \alpha_{\mathrm{S}}\right)$ into wild-type oocytes phenocopied the MIHR mutants. These results provide the molecular links between $\mathrm{MlH}$ stimulation and meiotic maturation initiation in hydrozoan oocytes. Molecular phylogeny grouped Clytia MIHR with a subset of bilaterian neuropeptide receptors, including neuropeptide $Y$, gonadotropin inhibitory hormone $(\mathrm{GnlH})$, pyroglutamylated RFamide, and luqin, all upstream regulators of sexual reproduction. This identification and functional characterization of a cnidarian peptide GPCR advances our understanding of oocyte maturation initiation and sheds light on the evolution of neuropeptide-hormone systems.

\section{Introduction}

Oocyte meiotic maturation is an essential process for animal sexual reproduction. It transforms the tetraploid, fully grown, ovarian oocyte into a haploid female gamete [1]. The core biochemical and cellular pathways operating within the oocyte during maturation are highly conserved between animals across the phylogenetic spectrum. Activation of the CyclinB-Cdk1 
from the CNRS and from Sorbonne University to the Laboratoire de Biliogie du Développement de Villefranche-sur-mer. Work done with the Service Aquariologie and the Villefranche-sur-mer Imaging platform of the Institut de la Mer de Villefranche was supported by EMBRC-France (ANR-10-INBS02). The funders had no role in study design, data collection and analysis, decision to publish, or preparation of the manuscript.

Competing interests: The authors have declared that no competing interests exist.

Abbreviations: 7TM, 7 transmembrane domain; ASW, artificial seawater; Br-cAMP, bromoadenosine $3^{\prime}, 5^{\prime}$-cyclic monophosphate; CAMP, cyclic adenosine monophosphate; $\mathrm{CHO}-\mathrm{K} 1$, Chinese Hamster ovary K1; FSH, folliclestimulating hormone; GnIH, gonadotropin inhibitory hormone; $\mathrm{GnRH}$, gonadotropin-releasing hormone; GPCR, G protein-coupled receptor; GST, Glutathione-S-Transferase; GVBD, germinal vesicle breakdown; HBSS, Hank's balanced salt solution; KO, knockout; LH, luteinizing hormone; MFSW, Millipore-filtered seawater; $\mathrm{MIH}$, maturationinducing hormone; MIHR, MIH receptor; P2Y, purinoceptor; PBS-T, PBS containing $0.1 \%$ Tween20; PKA, protein kinase A/cAMP-dependent protein kinase; QRFP, pyroglutamylated RFamide peptide; RNA-seq, RNA sequencing; sgRNA, small guide RNA; TIDE, Tracking of Indels by Decomposition. kinase complex assures meiotic progression from prophase I arrest into $\mathrm{M}$ phase, while parallel Mos-MAP kinase activation steers polar body formation as well as cytostatic arrest once maturation is complete [2,3]. In contrast, the upstream physiological processes vary widely, as does the molecular nature of the maturation-inducing hormones (MIHs) that act on the oocyte to trigger maturation $[1,4]$. This reflects clade-specific acquisition of endocrine tissues such as ovarian follicles, the corpus cardiacum/corpus allatum in insects, or the pituitary in vertebrates $[5,6]$. These tissues act downstream of other neuroendocrine sites such as the vertebrate hypothalamus to integrate environmental, behavioral, and physiological information in order to achieve optimal conditions for gamete development and release [7]. The complex evolutionary history of hormonal reproductive regulation has made it challenging to unravel the crucial regulatory events operating within the oocyte at the onset of maturation.

G protein-coupled receptors (GPCRs), the largest superfamily of integral transmembrane receptors [8], are good candidates to serve as MIH receptors (MIHRs). These 7-transmembrane domain proteins activate a variety of cytoplasmic signalling pathways via $\mathrm{G} \alpha$ and/or $\mathrm{G} \beta \gamma$ subunits that become released from receptor-associated heterotrimeric $\mathrm{G} \alpha \beta \gamma$ protein upon ligand binding [9-11]. Members of the four main $\mathrm{G} \alpha$ subunits classes, $G \alpha_{\mathrm{s}}, \mathrm{G} \alpha_{\mathrm{i}}, \mathrm{G} \alpha_{\mathrm{q}}$, and $\mathrm{G} \alpha_{12 / 13}$, associate variously with members of the vast GPCR family. In vertebrates, constitutively active GPCRs are coupled to $\mathrm{G} \alpha_{s}$, which stimulates adenylate cyclase to maintain high cytoplasmic cyclic adenosine monophosphate (cAMP) concentrations in ovarian oocytes [1214]. These high cAMP levels help hold the oocyte in an immature state, with the cell cycle arrested in meiotic prophase. The mechanisms by which MIHs override this arrest and initiate meiotic maturation vary between species and are not fully understood (see Discussion). In marked contrast, oocytes of many invertebrate species show a rise in cytoplasmic cAMP concentration upon MIH stimulation that is required for meiotic maturation [6]. In these species, GPCRs working through $\mathrm{G} \alpha_{\mathrm{s}}$ are thus good candidates to trigger oocyte maturation, rather than to inhibit it as in vertebrates. The identification of such receptors could help to understand the origin of this diversity by providing an evolutionary perspective.

Here, we identify the MIHR in the hydrozoan jellyfish Clytia hemisphaerica as a GPCR likely working through $\mathrm{G}_{\mathrm{s}}$, and determine its in vivo function. In Clytia and other hydrozoan species, MIH consists of PRPamide and related tetrapeptides that are released upon light stimulation from opsin-expressing gonad ectoderm cells, and act at the plasma membrane [15,16]. Neuropeptides such as these are of major importance in cnidarian biology, acting both as "neuroendocrine" mediators of physiological transitions, such as metamorphosis, as well as in fast neuromuscular transmission regulating swimming and feeding mediated by ligand-gated ion channels $[17,18]$. We uncovered an oocyte-expressed Class A GPCR in Clytia (MIHR) activated by MIH peptides, which is to our knowledge the first characterized cnidarian neuropeptide GPCR $[19,20]$. Antibody inhibition experiments further provided evidence that $\mathrm{G} \alpha_{s}$ links MIHR activation to cAMP production to trigger maturation [21,22]. CRISPR-Cas9 mediated mutation of the MIHR gene revealed an essential in vivo function of MIHR in initiating oocyte maturation. Phylogenetic analysis of the MIHR sequence identified an evolutionary link to a subset of bilaterian neuropeptide-hormone GPCR families, including several upstream regulators of reproduction. These results allow us to propose a new scenario for the evolution of hormonal signalling pathways regulating oocyte maturation.

\section{Results}

\section{Selection of candidate MIH GPCRs}

Amidated neuropeptides like Clytia MIH commonly signal through GPCRs, although other receptor types can also be used [23]. As the first step to select candidate MIH receptors, we 
compiled a comprehensive catalogue of Clytia GPCRs from a Clytia reference transcriptome covering all life cycle stages. Our bioinformatics pipelines first retrieved all sequences predicted to code for 7 transmembrane domain (7TM) proteins and bearing GPCR-related Pfam database tags. An initial list of 761 sequences was then assigned by Pfam to the three main GPCR classes: A (rhodopsin-like), B (secretin-like), and C (metabotropic glutamate-like) $[8,24]$ or to an "other" category (which included, for instance, sweet-taste receptors and cAMP-like receptors). The final dataset of 536 class-sorted putative Clytia GPCRs obtained after removal of duplicates (S1 Text) may be a slight overestimate due to some incorrectly identified or incomplete sequences. We focused on the 377 class-A GPCRs, because most neuropeptide GPCRs belong to this class $[8,25]$.

An important criterion for the selection of candidate MIH receptors from the class-A GPCR list was enrichment in oocytes (Fig 1A). We mapped Illumina HiSeq mRNA reads previously obtained from Clytia gonad tissues [16] and life cycle stage [26] against all putative GPCR sequences. Profile clustering revealed three groups of sequences with oocyte-enriched expression (S1 Fig). We further narrowed down the number of potential MIHRs from these expression groups to 96 sequences, taking into account also Pfam indicators and sequence similarity with a set of bilaterian GPCRs [25]. Finally we compiled a shortlist of 16 candidates for functional testing using high expression level in oocytes as the final selection criterion (Fig 1A; S2 Text).

\section{Identification of the Clytia MIH receptor by GPCR deorphanization assay}

We used a cell culture-based GPCR deorphanization assay to identify the MIH receptor from our candidate shortlist. cDNAs for each candidate were transfected into Chinese Hamster ovary $\mathrm{K} 1$ (CHO-K1) cells along with the promiscuous $\mathrm{G} \alpha$ protein $\mathrm{G} \alpha-16$, and an aequorinGFP luminescence reporter that measures $\mathrm{Ca}^{2+}$ mobilization downstream of this heterologous G $\alpha$ protein $[27,28]$. We first screened the 16 candidate Clytia GPCRs against a mixture of 33 synthetic amidated peptides (including MIHs) predicted to be generated from previously identified putative Clytia neuropeptide precursors [15] and one additional one identified from transcriptome data. Given our imperfect knowledge of pro-peptide processing in cnidarians, some of the synthetic peptides may not correspond to endogenous peptides [29,30]. Only one of the 16 GPCRs was activated by this peptide mixture. This receptor responded well to all 4 synthetic Clytia MIH tetrapeptides, as well as to related Cladonema MIH peptides that can also activate Clytia oocyte maturation, but not to other Clytia peptide mixtures or poorly active $\mathrm{MIH}$ penta-/tripeptides. We termed this Clytia GPCR the Maturation Inducing Hormone Receptor (MIHR). The activity of individual peptides at $1 \mu \mathrm{M}$ to stimulate the MIHR closely matched their in vivo ability to induce oocyte maturation [15] (Fig 1B).

The Clytia MIH amidated peptides are produced from two precursor genes Che-pp4 (generating multiple copies of WPRAamide, WPRYamide, and WPRPamide) and Che-pp1 (multiple copies of WPRPamide and RPRGamide) [15]. Their predicted structural similarity suggests they bind the same site on the receptor with different affinities. Dose-response curves for each of the 4 Clytia MIH neuropeptides, generated from three independent experiments, showed half maximal effective concentration $\left(\mathrm{EC}_{50}\right)$ values in the high-nanomolar or low-micromolar range for all $4 \mathrm{MIHs}$, with RPRYamide showing the highest activity and RPRGamide the lowest (Fig 1C). To our knowledge, Clytia MIH and MIHR are the first neuropeptide ligandGPCR pair demonstrated in a cnidarian.

\section{Phenotypes of MIHR mutant jellyfish}

To determine the function of MIHR in vivo, we generated Clytia MIHR knockout (KO) polyp colonies using CRISPR/Cas9 mutagenesis (see Methods). This gene-editing technique is very 

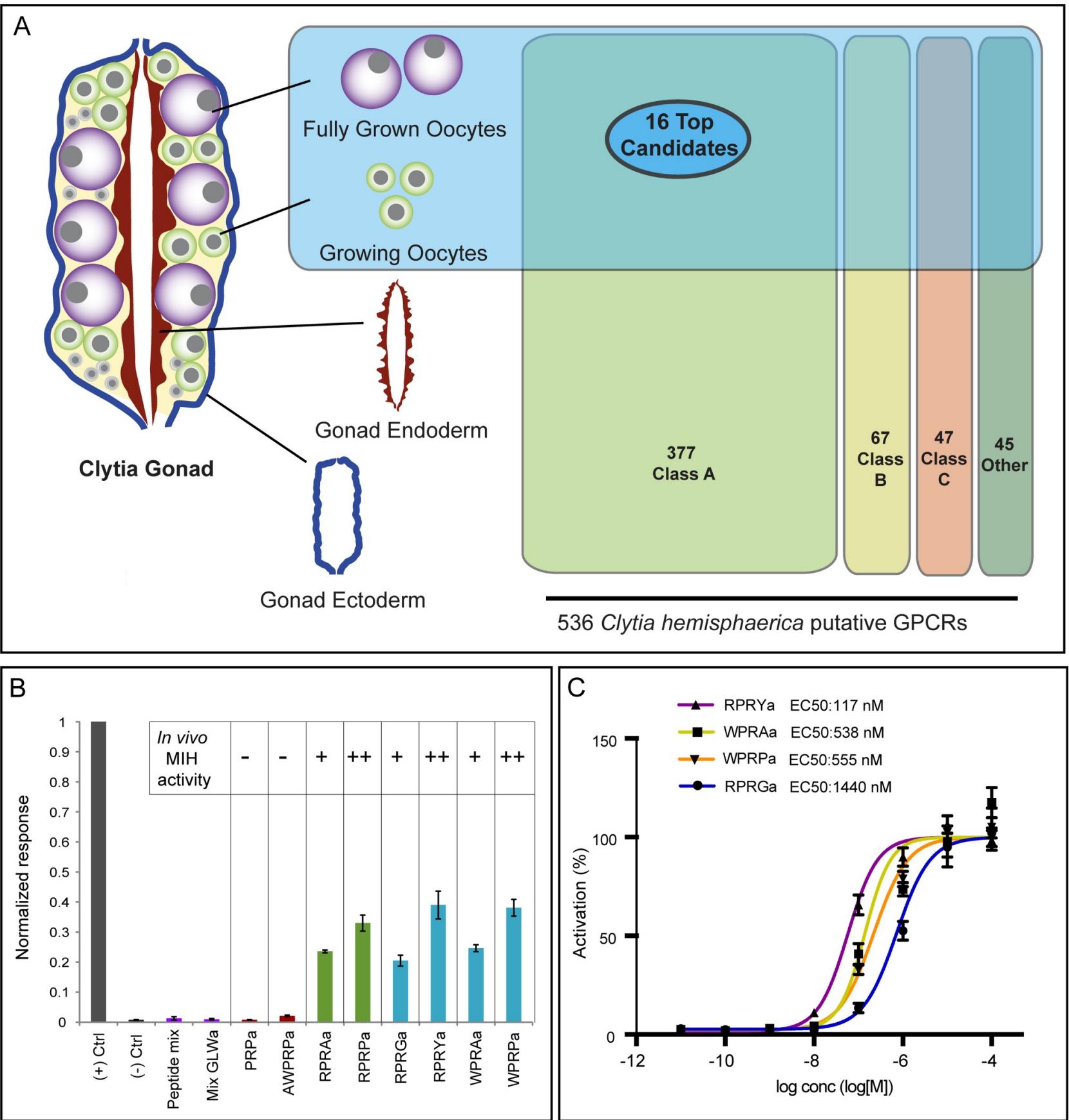

Fig 1. Identification of the Clytia MIHR. (A) Diagram of a Clytia gonad showing the different tissues used for RNA-seq and GPCR expression comparisons. A total of 536 putative GPCRs identified in Clytia mixed-stages transcriptome were assigned to the three main GPCR classes (A, B, C) or "other" based on Pfam signatures. The 16 top candidate MIH GPCRs were selected based on oocyte enrichment, relatedness to known bilaterian classA neuropeptide GPCRs, and Pfam information. (B) Luminescence response of CHO-K1 cells expressing the putative Clytia MIH GPCR treated with neuropeptide mixes lacking MIH activity (purple bars), MIH tetrapeptides identified from C. hemisphaerica (blue bars) or Cladonema radiatum (green bars), or related penta- and tripeptides previously shown to be ineffective in triggering oocyte maturation in vivo (red bars) [15]. Empty pcDNA3.1 vector was used as negative control and Platynereis FLamide and its receptor as a positive control (gray bars). Peptide concentrations all $1 \mu \mathrm{M}$. Absolute units of luminescence were normalized using the positive control; data are shown as mean \pm standard error of the mean $(n=3)$. Full datasets are available in S1 Data. MIH tetrapeptides were selectively able to activate the Clytia GPCR, the responses closely matching the in vivo MIH activity of each peptide tested on Clytia oocytes as indicated (summarized results from [15]). (C) Dose-response curves of Clytia MIHR challenged with four variant Clytia MIH tetrapeptides. One of three independent experiments with equivalent results is shown. Luminescence values were normalized relative to the maximum of fitted dose-response curves and are shown as mean \pm standard error of the mean $(n=3)$. Half maximal effective concentration $\left(\mathrm{EC}_{50}\right)$ values were calculated as means of 3 independent experiments. Full datasets from three independent experiments are available in S2 Data. CHO-K1, Chinese Hamster ovary K1; GPCR, G protein-coupled receptor; MIH, maturation-inducing hormone; MIHR, MIH receptor; RNAseq, RNA sequencing. 
effective in Clytia, allowing extensive bi-allelic mutation of target genes already in F0 polyp colonies [16]. Three guide RNAs designed to target the third transmembrane domain of the MIHR protein were tested by genotyping at the planula stage and the most effective one used to generate polyp colonies. After genotyping around the target site, we selected and propagated for phenotypic analysis six colonies showing a very low proportion or no detectable wild-type sequence and carrying mainly frameshift mutations (Table 1). All six mutant polyp colonies expanded slowly compared to wild-type colonies. They displayed variable morphologies, with two of them rambling pronouncedly away from the glass substrate (Fig 2A; Table 1), but all produced active gonozooids that budded baby medusae. Growth of these mutant baby medusae was slower for the six mutants than for wild types, but they were able to reach the full adult size of about $1 \mathrm{~cm}$ in diameter. The adult jellyfish all swam less vigorously than wild types. The slow growth of mutant polyps and medusae was not due to any obvious feeding problems: both forms could capture Artemia nauplii without difficulty.

Of the six MIHR mutant colonies, three produced male jellyfish and three females. In addition to the shared defects in growth and swimming behavior, they showed one of two distinct phenotypes affecting gonad development. For one female and one male MIHR mutant (n5-8 and n5-24, respectively), the gonads of the adult jellyfish developed poorly, failing to accumulate gametes as occurs during wild-type adult growth (Fig 2B). Examination of the gonads by confocal microscopy revealed the presence of small oocytes for n5-8 and a thin spermatogenic zone for n5-24. This suggested that mutation of the MIHR gene may directly or indirectly compromise gametogenesis in male and female jellyfish. In marked contrast, jellyfish from the four other MIHR mutant polyp colonies underwent gametogenesis to produce large numbers of fully grown oocytes (n5-13, n5-23; Fig 2C) or spermatozoids (n5-6, n5-10; Fig 2D). In the female n5-13 and n5-23 medusae, gonads were grossly inflated by accumulation of fully grown immature oocytes. As detailed below, we could demonstrate that this was due to failure in light-induced oocyte maturation and subsequent release of the unfertilized egg, and reflected inability of the oocytes to respond to $\mathrm{MIH}$, rather than a nonspecific oocyte maturation defect. In males, the gonads were markedly deformed and irregular. Following dark to light transitions that induced spawning in wild-type males, some local sperm release was observed from rupture sites of the gonad epithelium, but the sperm remained concentrated at the gonad surface and failed to disperse.

Table 1. Characteristics of MIHR mutant colonies.

\begin{tabular}{|c|c|c|c|c|}
\hline Colony name & Predominant mutations (minor mutations) & Medusa sex & Polyp colony* & Medusa gonads \\
\hline n5-23 & $-4 \mathrm{nt},+74 \mathrm{nt}(-8 \mathrm{nt})$ & Female & normal & Enlarged and deformed \\
\hline n5-8 & $-7 \mathrm{nt}(+11 \mathrm{nt})$ & Female & rambling & Poorly developed \\
\hline n5-13 & $-4 \mathrm{nt},-3 \mathrm{nt}$ & Female & rambling & Enlarged and deformed \\
\hline n5-24 & $-34 \mathrm{nt},+59 \mathrm{nt}$ & Male & normal & Poorly developed \\
\hline n5-10 & $-4 \mathrm{nt}(-6 \mathrm{nt},+2 \mathrm{nt})$ & Male & normal & Enlarged and deformed \\
\hline n5-6 & $-4 \mathrm{nt},-3 \mathrm{nt}(-2 \mathrm{nt})$ & Male & normal & Enlarged and deformed \\
\hline
\end{tabular}

${ }^{\#}$ Large deletions (-) and insertions (+) were detected by gel electrophoresis of PCR fragments amplified from genomic DNA (see Methods) and Sanger sequenced. They were recognized as major PCR bands of non-wild-type size. For PCR fragments migrating close to the predicted wild-type size, local nucleotide insertions and deletions were detected by TIDE analysis (see Methods). Genotypes were classed as "predominant" if they correspond to major PCR bands from gel analysis or were estimated by TIDE analysis as more than $20 \%$ of the genotype, and as "minor" if estimated at between $5 \%$ and $20 \%$ in TIDE analysis. Any additional local mutations estimated at under $5 \%$ by TIDE analysis are not included.

*See Fig 2A.

Abbreviations: MIHR, MIH receptor; TIDE, Tracking of Indels by Decomposition 

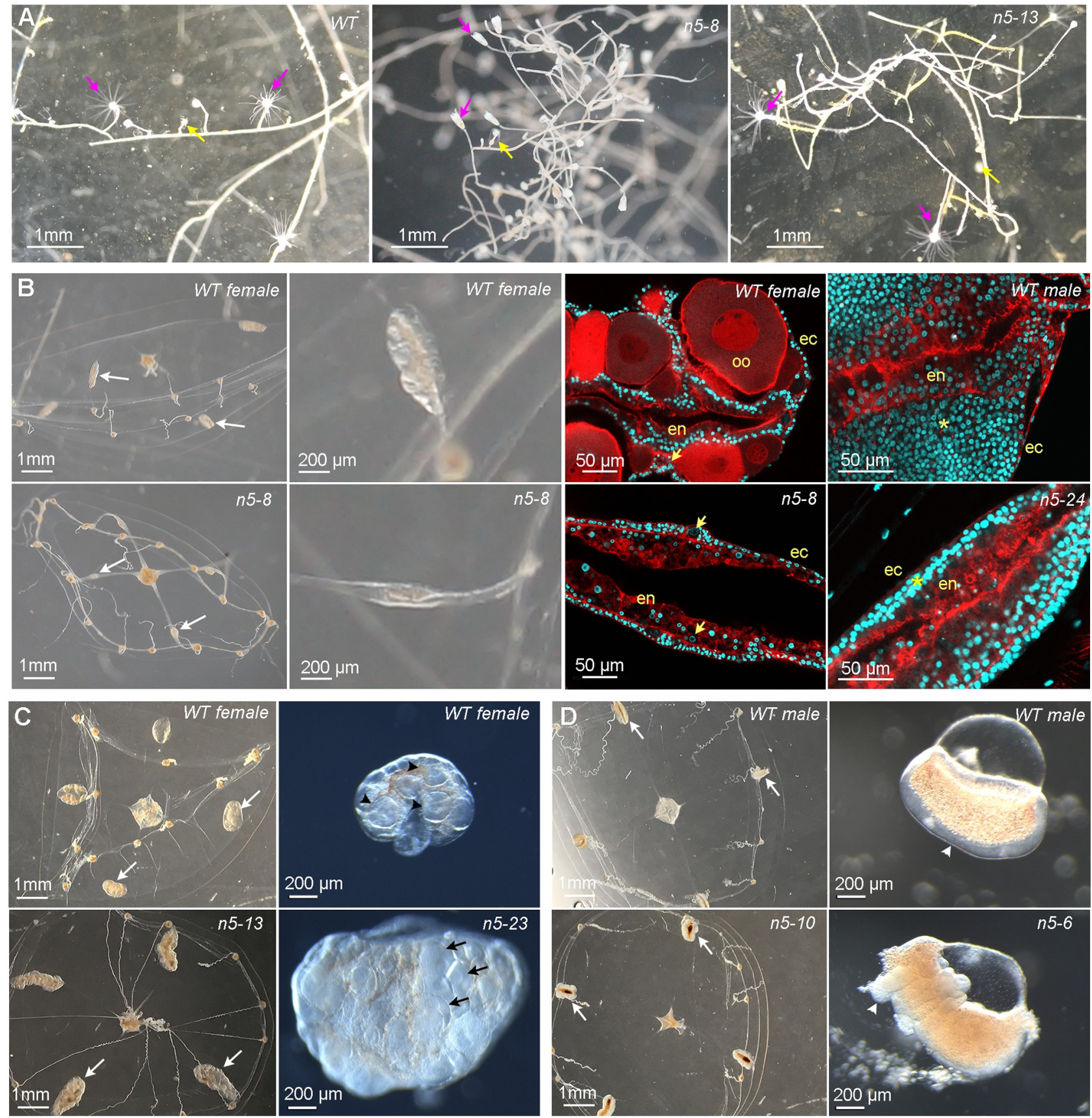

Fig 2. Phenotypes of Clytia MIHR mutants. Light and confocal microscope images of MIHR mutant F0 polyp colonies and jellyfish. (A) Morphology of a wild-type (WT) colony, Z11, and two MIHR mutant colonies (n5-8 and n5-13), as indicated. All MIHR mutant colonies contained gastrozooid and gonozooid polyps (pink and yellow arrows, respectively); however, the connecting stolons in some mutant colonies (see Table 1) were convoluted and frequently detached from the glass substrate, while stolons of WT colonies and the other mutant colonies were straight and adhered tightly. (B) Phenotypes of fully grown WT (top row) and mutant n5-8 or n5-24 (bottom row) jellyfish. Mutant and WT jellyfish show very similar morphology, but gonads developed poorly in these mutants, as shown by white arrows in the first column and at higher magnification in the second column. The third and fourth columns are confocal microscope images through the gonads of adult jellyfish from females and males, respectively; nuclei are stained with Hoechst 33342 (cyan) and F-actin with Phalloidin (red). In the n5-8 female gonad, small oocytes (arrows) can be detected between the endodermal (en) and ectodermal (ec) layers, but no large growing oocytes (oo) are present compared to the WT female gonad. In the n5-24 male gonad, the spermatogenic zone (asterisk) between endoderm and ectoderm is much thinner than in the WT male gonad. (C) Comparison of mutant n5-23 and n513 (bottom row) female medusae gonads (white arrows) swollen by an accumulation of large oocytes to WT (Z11) female medusae (top row). Right panels show gonads dissected from 3-week-old n5-23 medusae 10 hours after a light cue that induced spawning in the WT but not the mutant gonad. Black arrowheads indicate large growing oocytes in the WT gonad and black arrows indicate fully grown oocytes in the mutant gonad. (D) Adult mutant n5-10 and n5-6 male medusa (bottom row) compared to WT (Z13) male medusae (top row) have deformed gonads (white arrows). Right panels show isolated gonads, illustrating the thickened and irregular spermatogenic layer (arrowheads) in the mutant. Scale bars as indicated. MIHR, MIH receptor.

https://doi.org/10.1371/journal.pbio.3000614.g002 
The origin of the two opposite gonad defects observed in jellyfish from different mutant MIHR colonies, i.e., poorly developed versus swollen with gametes, is not clear. There was no obvious relationship between gonad phenotype and genotype at the CRISPR target site (Table 1). All mutations detectable at above 5\% in genomic DNA extracted from the colonies were frameshift, with the exception of minor 3-nt and 6-nt deletions in colonies n5-13 and n5-10, respectively. The possibility remains that in some of the colonies, small populations of cells with nonframeshift mutations, or residual wild-type cells, could directly or indirectly facilitate gonad development. We also cannot rule out that the poor gonad development in MIHR mutants n5-8 and n5-24 results from off-target mutations induced by Cas9, even though we prescreened the CRISPR target sites against the Clytia genome (see Methods). On the other hand, off-target mutations are unlikely to explain the oocyte maturation failure, which could be selectively reversed by treatment with cAMP analogues (see below). We favor the explanation that the poor overall growth of the jellyfish observed in all MIHR mutants affected gamete growth within the gonads more severely in some strains than others, perhaps due to variation in their genetic backgrounds.

This initial phenotype analysis of jellyfish from six independent MIHR mutant F0 polyp colonies suggests both global and gonad-specific roles for MIHR. Firstly, it may have nonessential functions in regulating medusa swimming and medusa growth that may impair gametogenesis in some cases, although the specificity of these phenotypes is not fully confirmed. Secondly, it has a specific role in regulating gamete maturation and release. For females, the overaccumulation of immature, fully grown oocytes in medusae from two independent MIHR mutants strongly supported the identity of this GPCR as the MIH receptor. Its role in oocytes is characterized further below.

\section{Clytia MIHR is expressed in oocytes and also in tentacle cells}

The observed defects in MIHR mutant jellyfish suggested that this receptor may have roles both in the gonads and other sites. In situ hybridization detection of MIHR mRNA in adult jellyfish (medusae) and in isolated gonads (Fig 3) supported this idea. Strong expression was detected in developing oocytes and in male gametes, consistent with the ability of MIH to induce male spawning [15]. Expression was also detected in clusters of small somatic cells located within each tentacle bulb. Individual cells from these clusters extended in a line along each tentacle (Fig 3A, 3B and 3C). MIHR in tentacle cells could potentially respond to MIH neuropeptides produced by neural/neuroendocrine cells of the endodermal gastrovascular system, detectable using an antibody recognizing the PRPamide peptides produced from both Che-PP1 and ChePP4 (anti-PRPa [15]; Fig 3D). These two precursors are expressed respectively in association with the manubrium and tentacle, as well as being co-expressed in scattered cells of the gonad [15]. Comparison of in situ hybridization patterns for MIHR and $M I H$ showed that the ligand and receptor-expressing cells in the tentacles have distinct distributions: the single file of MIHR cells lies on the rounded oral side [31], whereas the MIH cells form two flanking lines (Fig 3B and 3C). No MIHR-expressing cells were detected in the manubrium, only nonspecific staining of the manubrium floor. Regulation of tentacle contractions by MIHR-expressing cells in the tentacles in response to $\mathrm{MIH}$ produced in the gastrovascular system, integrated in a wider neuronal system, for instance including RFamide expressing cells [32], could account for the sluggish movement and poor growth of MIHR mutant medusae. Specific assays should be devised in the future to examine this hypothesis in detail.

\section{Clytia MIHR is the essential oocyte receptor for oocyte maturation}

We used jellyfish from the two MIHR female mutant colonies that showed the swollen-gonad phenotype (n5-13 and n5-23) to characterize the role of this GPCR in oocyte maturation. We performed a series of oocyte maturation and spawning assays, comparing the responses of 
A

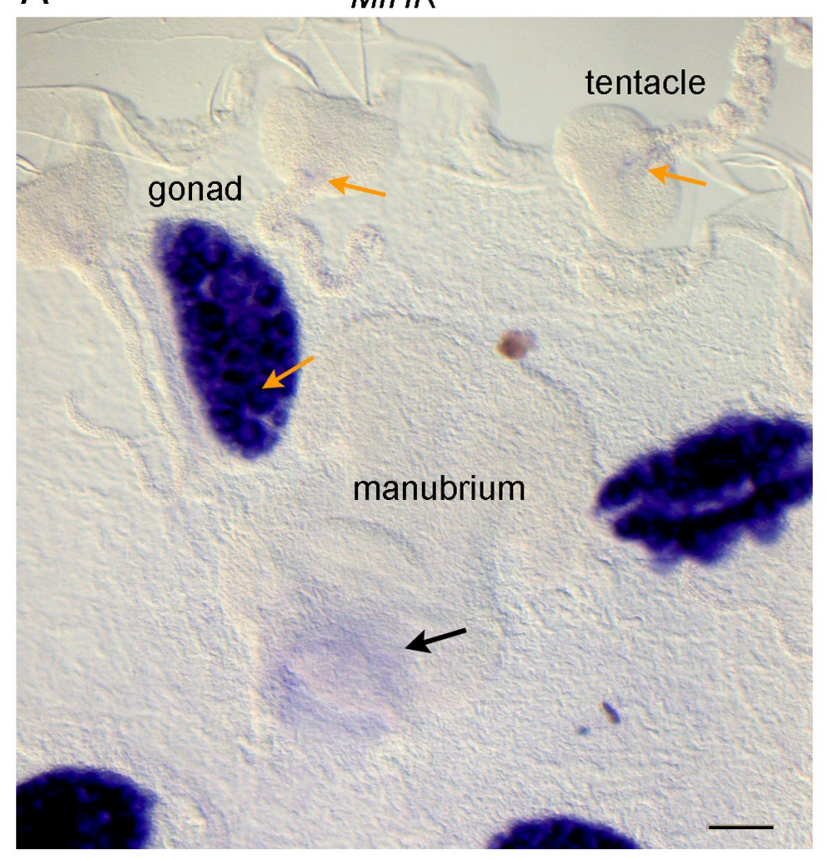

D
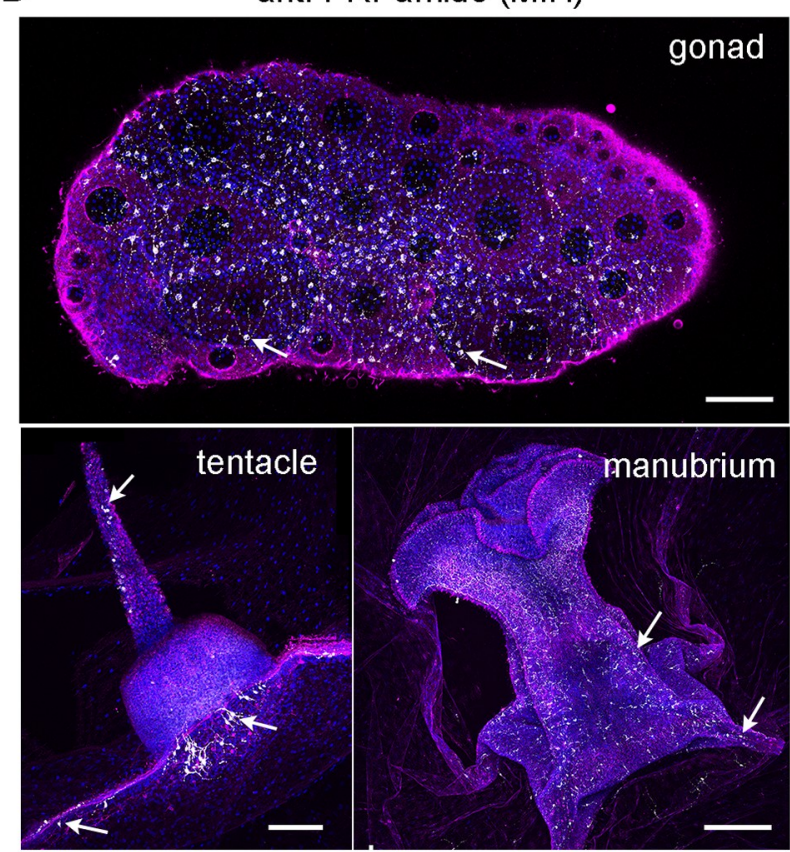

B

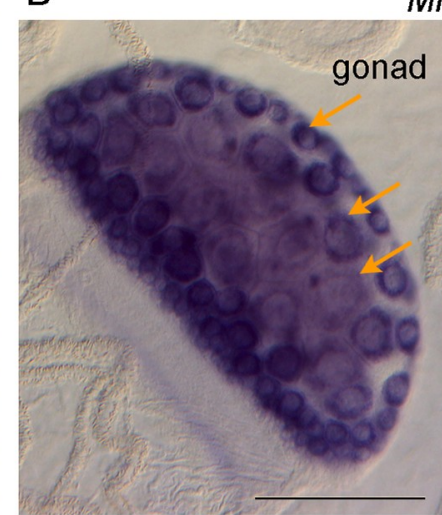

MIHR

C
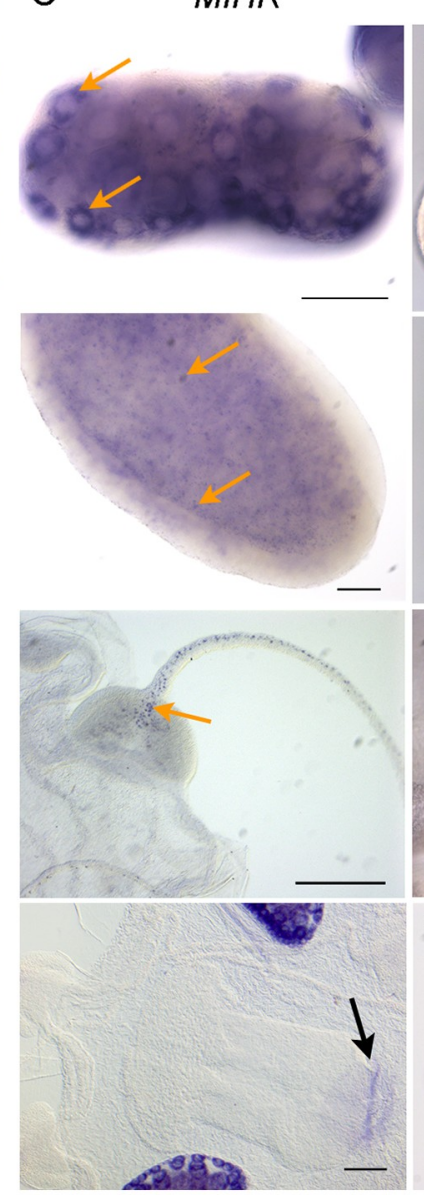

tentacle

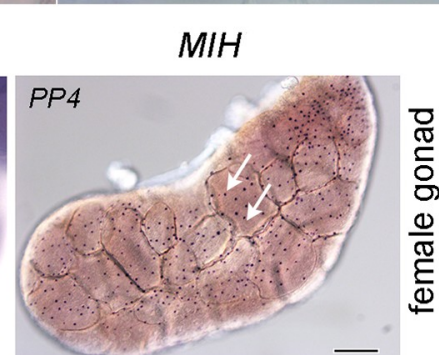

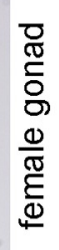
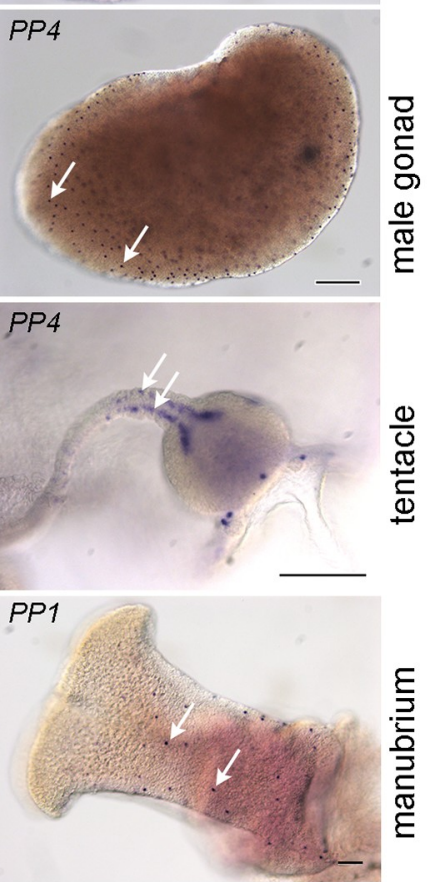

Fig 3. Sites of $M I H R$ expression in the Clytia medusa. (A) In situ hybridization detection of MIHR mRNA in a young adult Clytia female medusa. Strong purple MIHR signal (orange arrows) was detected in oocytes within the gonads, as well as in scattered cells in tentacles. (B) Higher magnification images of MIHR mRNA detected in young adult medusae; with the gonad, each oocyte (e.g., at orange arrows) has an unstained nucleus. The intensity of labelling in individual oocytes decreases as they grow due to dilution of cytosol with yolk. In the tentacle, a row of individual MIHR-positive putative neural cells can be clearly distinguished leading from the center of the bulb on its oral face. (C) Comparison of the distribution of the MIH receptor and ligand expressing cells in different medusa structures as labelled, detected by in situ hybridization using probes to MIHR (top row) and to the MIH peptide precursors PP1 and/or PP4 as indicated (bottom row). Orange arrows point to oocytes, developing spermatozoa and tentacle MIHR cells, and white arrows indicate MIH cells. The focal plane in the male gonad image is through the center to illustrate the position of the MIH cells in the ectodermal layer. Weak staining at the base of the manubrium (black arrow) in A and B is frequently observed with probes for many genes and is probably due to a specific trapping of the color reagent. Scale bars: $100 \mu \mathrm{m}$. (D) Confocal images of the three main sites of MIH-expressing cells (white arrows) in medusae, visualized using anti-PRPamide antibody (MIH: white), anti-tyrosinated tubulin (magenta), and Hoechst staining of nuclei (blue). Summed z-stacks are shown in all cases except for the gonad tubulin and DNA staining, where a single plane was selected through the center of the gonad. All scale bars: $100 \mu \mathrm{m}$. MIH, maturation-inducing hormone; MIHR, MIH receptor.

https://doi.org/10.1371/journal.pbio.3000614.g003 
wild-type and MIHR mutant isolated gonads and oocytes to different stimuli (Fig 4). Isolated wild-type gonads underwent oocyte maturation and spawning in response to light stimulation or treatment with the synthetic MIH peptide WPRPamide (100 nM) as previously shown [15], but MIHR mutant gonads did not respond (Fig $4 \mathrm{~A}$ and $4 \mathrm{~B}$ ). In contrast, treatment with $4 \mathrm{mM}$ bromoadenosine $3^{\prime}, 5^{\prime}$-cyclic monophosphate (Br-cAMP), a cell-permeable analogue of cAMP that induces hydrozoan oocyte maturation by mimicking the early cytoplasmic cAMP rise [3,21], rescued the phenotype of MIHR mutant gonads, efficiently triggering oocyte maturation and spawning. Br-cAMP treatments but not MIH peptides also promoted maturation of isolated fully grown MIHR mutant oocytes (Fig 4C). Br-cAMP-matured MIHR mutant oocytes could be fertilized to develop into planula larvae, although they had lower development and metamorphosis rates than wild-type oocytes. This demonstration of a cAMP-reversible maturation initiation failure in mutant female jellyfish confirmed that the Clytia MIHR has an essential in vivo function as the oocyte receptor for MIH.

\section{MIH-induced oocyte maturation blocked by an inhibitory $\mathrm{G}_{\mathrm{s}}$ antibody}

GPCR activation can lead to a cytoplasmic cAMP concentration rise in the responding cell as a result of adenylate cyclase stimulation via $S$ type $G \alpha$ subunits of heterotrimeric $G$ proteins. We tested the role of $\mathrm{G \alpha}_{\mathrm{s}}$ in Clytia oocyte maturation by injecting isolated oocytes with a specific inhibitory antibody previously shown to cause meiotic maturation of mouse, Xenopus, and zebrafish oocytes $[12,33,34]$. All oocytes were tested for maturation competence by incubation at the end of the experiment in Br-cAMP. Any that failed to mature when treated with $\mathrm{Br}$-cAMP were discounted in the analyses. Oocytes injected with anti-G $\alpha_{s}$ responded less efficiently than oocytes injected with PBS or a control anti-Glutathione-S-Transferase (GST) antibody when treated with synthetic MIH at low and then high doses (10 nM then $100 \mathrm{nM}$ WPRPamide; one of three equivalent experiments documented in Fig 5A). These results strongly suggest that MIHR acts mainly through $\mathrm{G \alpha}_{\mathrm{s}}$.

Based on these findings, we can now propose a model for maturation initiation in Clytia oocytes through MIH, MIHR, G $\alpha_{s}$, and cAMP (Fig 5B). A light cue triggers MIH release from neuroendocrine-type cells in the gonad ectoderm via an essential opsin protein [16]. The MIH peptides act on MIHR at the oocyte surface to promote $\mathrm{G} \alpha_{\mathrm{s}}$ activation, stimulating adenylate cyclase and thus promoting an increase in cytoplasmic cAMP concentration, essential for the transition into meiotic $\mathrm{M}$ phase.

\section{Clytia MIHR is related to a bilaterian superfamily of neuropeptide hormone receptors}

Much progress has been made in understanding the relationships between GPCR-neuropeptide families between protostomes and deuterostomes [20,25,28,35,36], and more recently with those in acoels and cnidarians [37]. We performed sequence-similarity-based clustering to explore the relationship of the Clytia MIHR sequence with known GPCR families in Bilateria using established datasets from human and the annelid Platynereis [25,28] (Fig 6A). The Clytia MIHR fell within the majority group of cnidarian GPCRs that cluster with a superfamily of peptide hormone receptors, including human neuropeptide $\mathrm{Y}$, neuropeptide FF, tachykinin, orexin, elevenin, and EFLGa/thyrotropin-releasing hormone, as well as luqin from Platynereis (Fig 6B). Adding to this analysis sequences recovered from the anthozoan cnidarian Nematostella highlighted the extensive independent expansion of the GPCR-A family since cnidarian and bilaterian neuropeptide systems split [37]. This analysis demonstrated that the MIHR group does not contain any of the GPCRs directly involved in controlling oocyte maturation in vertebrates, including the constitutively active GPR3, gonadotropin-releasing hormone 

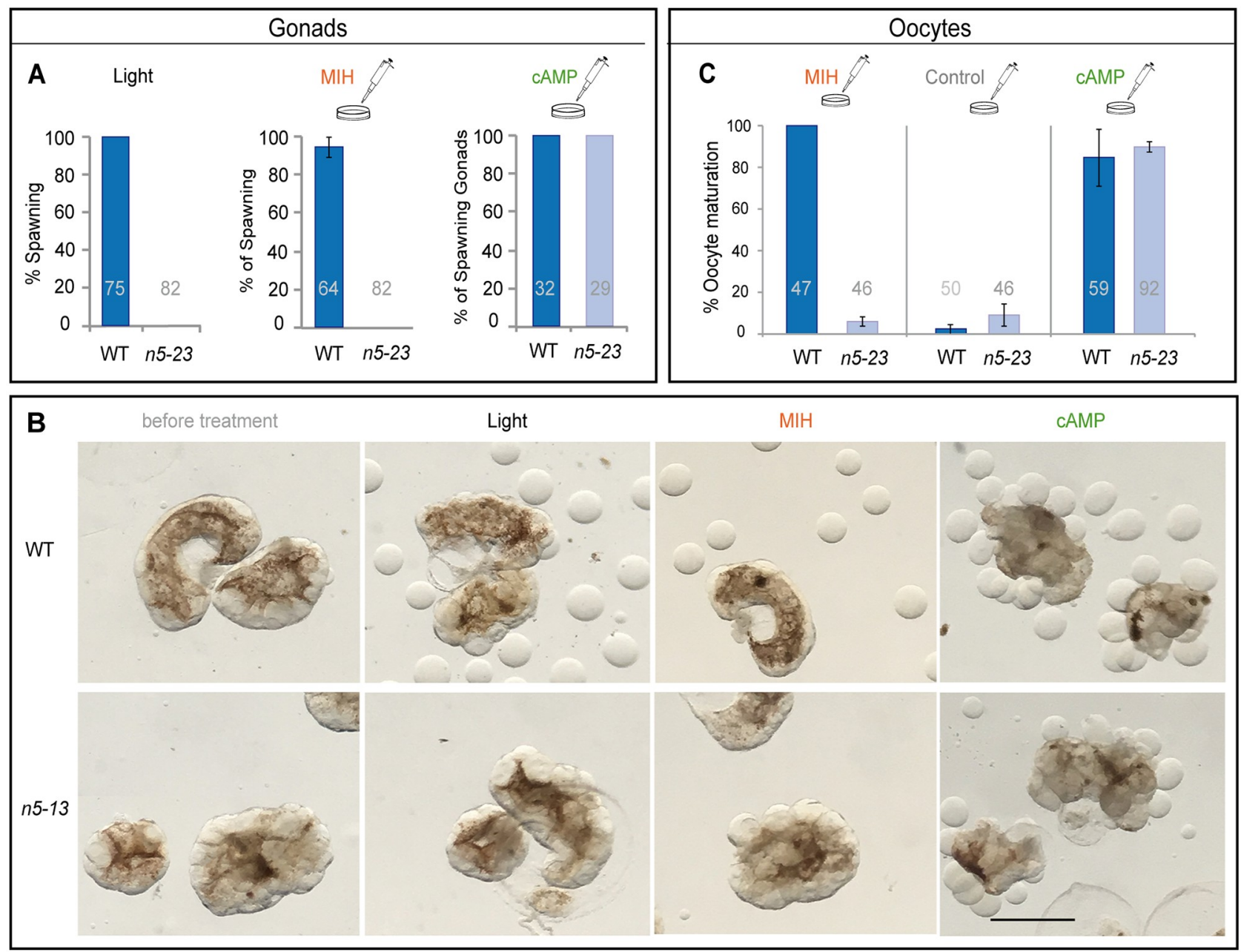

Fig 4. Oocyte maturation failure in MIHR mutant medusae. Oocyte maturation assays performed using isolated gonads (A, B) or isolated oocytes (C) from MIHR mutant jellyfish compared to WT. In A and C, bar heights represent mean percentages of 3 independent experiments and error bars show standard deviations. Total gonad or oocyte numbers for each treatment are indicated in gray. (A) Spawning response of isolated gonads from WT and n5-23 female medusae. Three treatments were compared as indicated above each panel: Light: light stimulation after incubation in the dark; MIH: treatment of light-maintained gonads with $100 \mathrm{nM}$ WPRPamide; cAMP: treatment of light-maintained gonads with $4 \mathrm{mM} \mathrm{Br}$-cAMP. No oocyte maturation or spawning was observed in MIHR KO gonads upon light stimulation or MIH treatment, while Br-cAMP treatment provoked oocyte maturation and spawning. The Fisher exact test showed significant differences $(\mathrm{F}=0)$ between wild-type and mutant responses to light and $\mathrm{MIH}$, but not for the cAMP treatment $(\mathrm{F}=1)$. Full datasets from three independent experiments are available in S3 Data. (B) Light microscope images illustrating gonads from an equivalent experiment performed with n5-13 female MIHR mutant medusae 120 minutes after the indicated treatments. Scale bar: $500 \mu \mathrm{m}$. (C) Response of fully grown oocytes isolated from WT and n5-23 MIHR mutant gonads to MIH and Br-cAMP treatments as in A. Both treatments triggered maturation of WT oocytes, visible after 20 to 30 minutes as germinal vesicle breakdown (GVBD), but only Br-cAMP induced maturation of MIHR KO oocytes. Control experiments using the Br-cAMP solvent (distilled water) showed a low level of spontaneous maturation in both cases. The Fisher exact test did not show significant differences between WT and mutant oocytes in the control $(\mathrm{F}=0.101)$ or cAMP-treated $(\mathrm{F}=0.216)$ groups, but did so in the MIH assays $(\mathrm{F}=0)$. Full datasets from 3 independent experiments are available in S3 Data. $\mathrm{Br}$-cAMP, bromoadenosine $3^{\prime}, 5^{\prime}$-cyclic monophosphate; cAMP, cyclic adenosine monophosphate; KO, knockout; MIH, maturation-inducing hormone; $M I H R$, MIH receptor; WT, wild-type.

https://doi.org/10.1371/journal.pbio.3000614.g004

(GnRH) receptor, or luteinizing hormone (LH)/follicle-stimulating hormone (FSH) receptor (see Introduction). A GPCR from Nematostella annotated as a GnRH receptor [38] associates with a distinct "superfamily" including the bilaterian $\mathrm{GnRH}$, vasotocin, CCAP, corazonin, and achatin receptor families.

Maximum likelihood phylogenetic analyses of the large GPCR cluster containing MIHR confirmed phylogenetic support for a GPCR "superfamily" associating two distinct cnidarian 

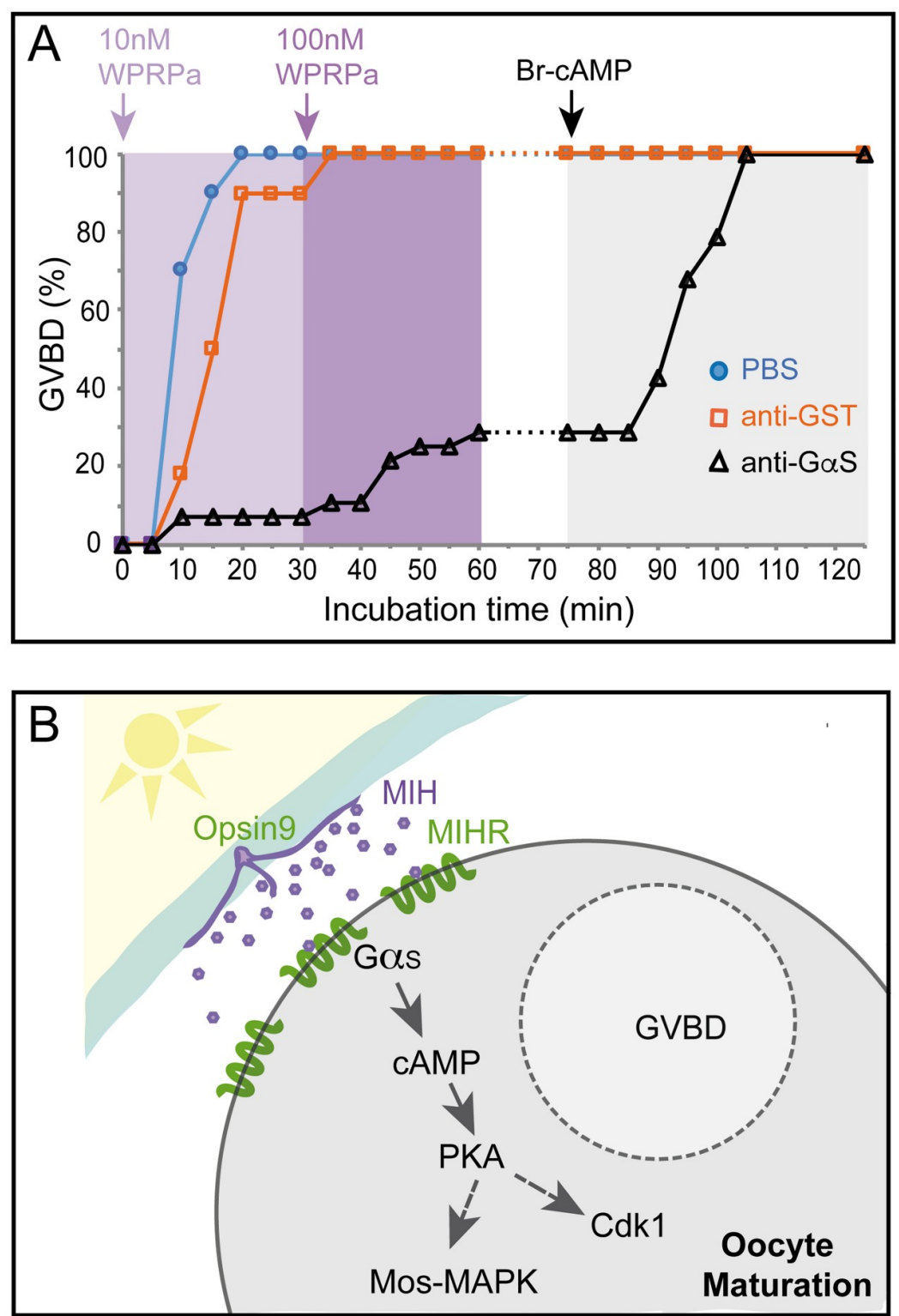

Fig 5. Involvement of $\mathrm{G \alpha}_{\mathrm{s}}$ in Clytia oocyte maturation. (A) Results of an antibody inhibition experiment. Maturation response (scored as percent GVBD over time) of isolated oocytes injected with antibodies or buffer, then challenged first with a low dose of MIH (10 nM WPRPamide), then with a higher dose (100 nM WPRPamide), and finally with Br-cAMP to verify maturation competence, as indicated by the colored arrows and background shading. Oocytes injected with PBS (blue circles) or a control anti-GST antibody (orange squares) responded efficiently to MIH, whereas very few oocytes injected with anti-G $\alpha_{\mathrm{s}}$ (black triangles) underwent GVBD after treatment with the low dose of $\mathrm{MIH}$ and only $29 \%$ following the high dose. The number of oocytes per group in this experiment was 30, 28, and 30, respectively. All of them had undergone GVBD by the end of the experiment. Times from the start of the first incubation are shown on the $\mathrm{x}$-axis. Full datasets from five independent experiments are available in S4 Data. (B) Scheme illustrating the proposed cascade initiating Clytia oocyte maturation initiation. Following light stimulation after a dark period, Opsin9 mediates release of MIH neuropeptides from specialized cells (purple) of the gonad ectoderm (cyan). Activation of the MIHR (green) at the oocyte surface releases $G \alpha_{S}$ to promote an increase in cytoplasmic cAMP, activating PKA. Unknown PKA substrates likely trigger in parallel Cdk1 activation and thus GVBD, and Mos1 synthesis to initiate the MAPK cascade.; Br-cAMP, bromoadenosine $3^{\prime}, 5^{\prime}$-cyclic monophosphate; GST, Glutathione-S-Transferase; GVBD, germinal vesicle breakdown; MIH, maturation-inducing hormone; MIHR, $\mathrm{MIH}$ receptor; PKA, protein kinase $\mathrm{A}$

https://doi.org/10.1371/journal.pbio.3000614.g005 
A
A $\quad \cdots \therefore \cdots \cdots$

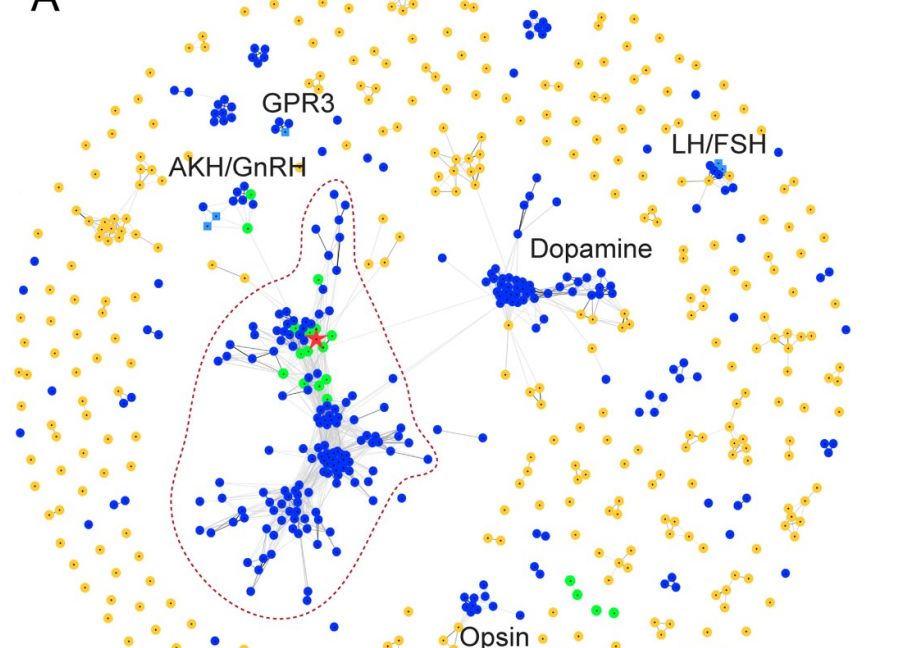

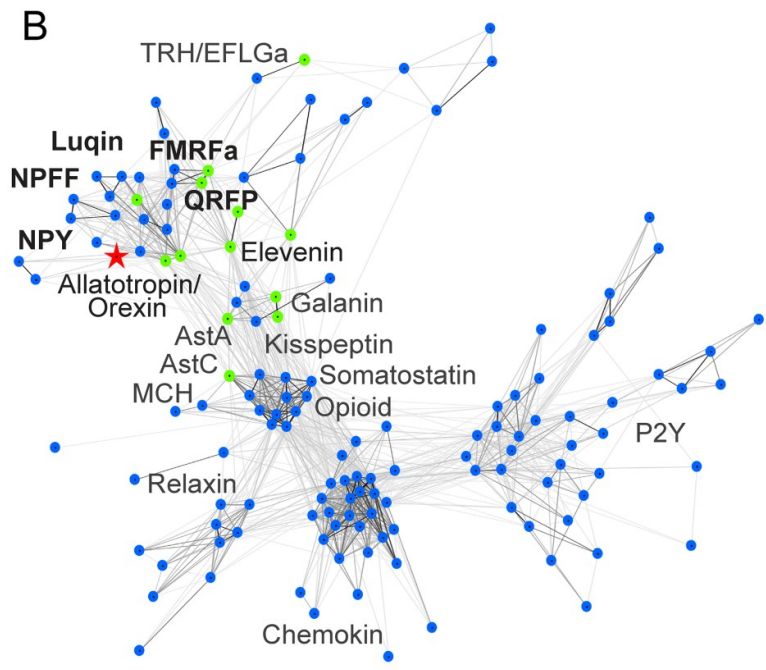

p-value Homo

$1 \mathrm{e}-120$

1e-40 Nematostella

Clytia - MIHR

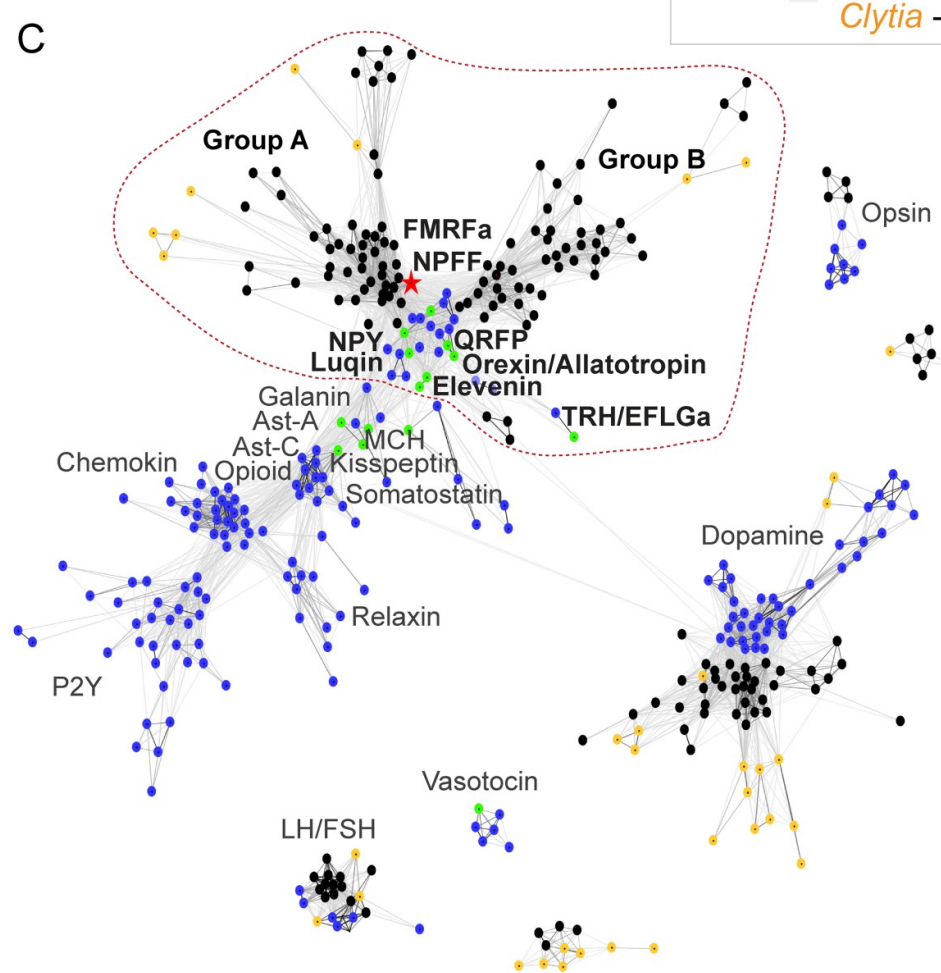

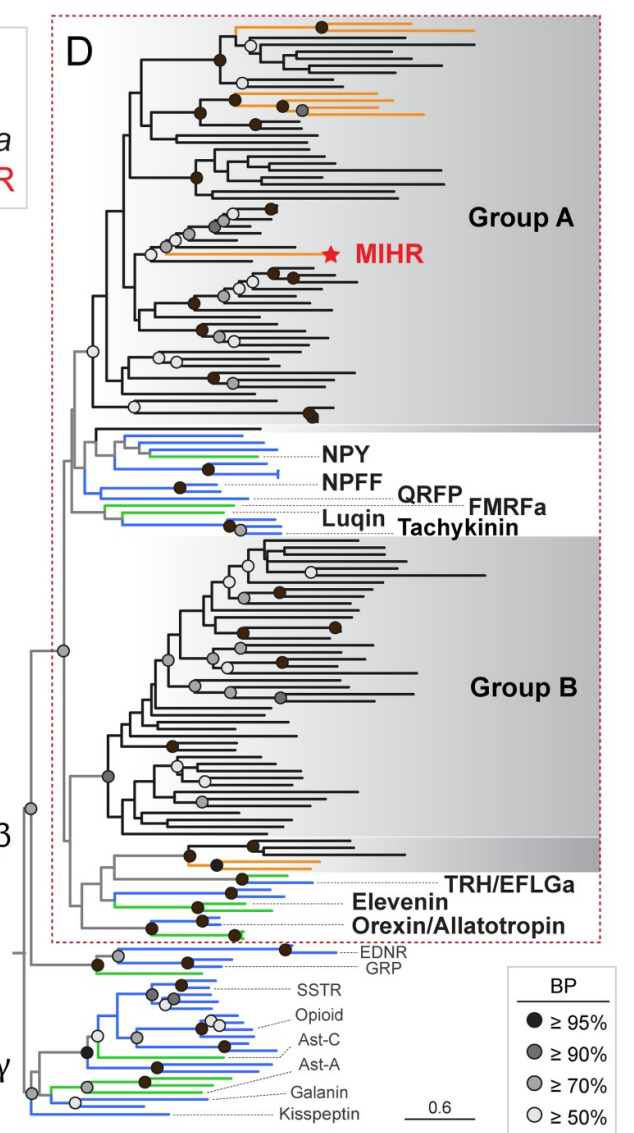

Fig 6. Relationship of Clytia MIHR to bilaterian neuropeptide hormone GPCRs. (A) Sequence-similarity-based clustering using Clans2 of all identified class-A GPCRs from Clytia, human (olfactory receptors excluded), and Platynereis deorphanized GPCRs [28] BLASTP $p$-value < 1e-40. (B) Cluster map of the largest cluster (circled in red in A), keeping only sequences that show at least 2 connections with the central cluster. BLASTP $p$ value $<1 \mathrm{e}-40$. (C) More stringent cluster map ( $p$-value $<1 \mathrm{e}-50)$ of the same sequences as in (A) plus all Nematostella GPCR-A sequences. Only clusters containing at least 5 sequences from at least 2 species were kept. All connections with $p$-value $<1 \mathrm{e}-40$ are shown. (D) Maximum likelihood analysis of the sequences contained inside the dashed area shown in (C) using RaxML (PROTGAMMAGTR) with 500 Bootstrap replicates (BR). Rhodopsin beta GPCRs are rooted against rhodopsin gamma GPCRs [37]. Tree file provided in S2 Fig. Color code: Homo sapiens: blue, Platynereis dumerilli: green, Nematostella vectensis: black, Clytia: orange. Red star: Clytia MIHR. FSH, follicle-stimulating hormone; GnRH, gonadotropin-releasing hormone; GPCR, G protein-coupled receptor; GPR3, G protein-coupled receptor 3; LH, luteinizing hormone; MIHR, MIH receptor; NPY, neuropeptide Y; P2Y, purinoceptor; QRFP, pyroglutamylated RFamide peptide.

https://doi.org/10.1371/journal.pbio.3000614.g006 
groups (groups A and B in Fig 6C and 6D) with a set of bilaterian neuropeptide hormone receptors [37]. Cnidarian GPCR group A contained Clytia MIHR, six other Clytia GPCRs, and a large number of Nematostella receptors. It showed weakly supported association with a set of bilaterian peptide hormone receptor families, including those for neuropeptide Y/neuropeptide F, gonadotropin inhibitory hormone $(\mathrm{GnIH})$ /neuropeptide FF, RYa/Luqin, tachykinin, and pyroglutamylated RFamide peptide (QRFP) [25,28,37]. Group B included two Clytia GPCRs and associated with further bilaterian neurohormonal receptor families, including elevenin, EFLGa/TRH, and orexin/allatotropin receptors (Fig 6C and 6D). The low support values for many deep branch relationships within this superfamily make it difficult to determine definitive evolutionary relationships between the neuropeptide hormone receptors and cnidarian groups A and B GPCRs. We can nevertheless conclude that Clytia MIHR, along with eight other Clytia GPCRs and a very large group of Nematostella GPCRs, have a common ancestor with a subset of bilaterian peptide hormone receptor families that includes many involved in regulating sexual reproduction and feeding.

\section{Discussion}

GPCR deorphanization followed by targeted gene mutation allowed us to identify Clytia MIHR as the neuropeptide receptor responsible for initiating oocyte meiotic maturation. MIHR female mutant medusae accumulated fully grown oocytes that failed to mature unless treated with cAMP analogues to bypass the receptor. We further provided evidence that a $\mathrm{G} \alpha_{\mathrm{s}}$ subunit links MIHR activation to the increase in cytoplasmic cAMP concentration in the oocyte that initiates maturation. MIHR belongs to a superfamily of neuroendocrine GPCRs involved in regulating reproduction but also nutrition, as well as diverse other physiological processes. Clytia MIH and MIHR are expressed in the gastrovascular system, tentacles, and possibly elsewhere and likely have other roles than in gamete maturation. Our findings thus open doors to an improved understanding of the vital animal process of oocyte maturation and help to shed light on the evolution of the neurohormonal regulation of sexual reproduction.

\section{An oocyte receptor for maturation initiation}

Our work shows that Clytia MIHR is entirely responsible for the oocyte response to MIH, allowing us to fill in the main molecular actors leading to oocyte meiotic maturation (Fig 5B): MIH is released from specialized gonad ectoderm cells in response to a dark to light transition at dawn via the essential photoresponsive GPCR Opsin9 [16]. Binding of MIH to MIHR at the oocyte surface is likely swiftly followed by a rise in cytoplasmic cAMP levels in the oocyte to activate cAMP-dependent protein kinase (PKA), as has been shown in other hydrozoan species [22]. Our antibody inhibition experiments strongly implicate $\mathrm{G} \alpha_{\mathrm{s}}$-stimulated adenylate cyclase activity in driving this cAMP rise. PKA leads to activation of the Cdk1-CyclinB and Mos-MAP kinase systems, which have highly conserved roles in oocyte maturation [39,40]. To complete the full chain of events between MIH secretion and meiotic maturation will require the identification of PKA substrates from Clytia oocytes that interact with regulators of Mos translation and/or Cdk1-CyclinB autoactivation.

cAMP rises initiate oocyte maturation not only in hydrozoans but also in a diverse range of protostome and deuterostome species [6], so it is tempting to speculate that the straightforward pathway linking MIH secretion to meiotic maturation in Clytia may have retained its main features from a distant cnidarian-bilaterian ancestor. A useful step towards testing this idea would be to search for MIHR superfamily GPCRs in oocytes of nemertean, ascidian, bivalves, or ophiuroid species that depend on cAMP signalling for maturation. If confirmed as 
the ancestral state, the Clytia MIH-MIHR system could provide a paradigm for the molecular dissection of a common, cAMP-stimulated mechanism for oocyte meiotic resumption.

\section{Evolution of reproductive regulation}

The role of cAMP in initiating oocyte maturation is not universal. In some cases, such as in starfish, it has no significant role [41], while in many vertebrate species, high cAMP levels in the ovarian oocyte have been strongly implicated in maintaining the prophase arrest. Clues to understanding how these marked differences arose during evolution may be found by considering the GPCRs involved in regulating gamete maturation and release across species. In vertebrates, GPCRs are involved in triggering oocyte maturation at several levels along the hypothalamus-pituitary-gonadal axis (Fig 7). At the level of the ovarian oocyte, constitutively active GPCRs of the GPR3/6/12 family help maintain prophase arrest via $\mathrm{G}_{\mathrm{s}}$-cAMP [12-14]. $\mathrm{LH}$ receptors in the surrounding follicle cells provide upstream signalling also via $\mathrm{G} \alpha_{\mathrm{s}}$-cAMP. The follicle cells signal is transmitted to the oocyte in mouse via a cGMP decrease through gap junctions [42]. In fish and amphibians, follicle cells secrete steroid hormones that act on one or more types of oocyte membrane receptor. The extent and importance of the cAMP drop observed at maturation initiation vary in different systems studied, and other signaling pathways are likely to be important, at least in some species $[39,40,43,44,45,46]$. Upstream of the vertebrate follicle, $\mathrm{LH}$ production from the pituitary is under control of the master reproductive regulator $\mathrm{GnRH}$ receptor acting via $\mathrm{G} \alpha_{\mathrm{q}}$ and cytoplasmic $\mathrm{Ca}^{++}$release. Many other hormone-GPCR pairs influence production of GnRH by the hypothalamus, as well as the gonadotropins LH and FSH by the pituitary. Molecular phylogeny showed that Clytia MIHR is not closely related to receptors of the core hypothalamus-pituitary-gonadal GPCRs, but rather forms a superfamily with receptors of these "upstream" neuropeptide hormones, notably GnIH, QRFP, Neuropeptide Y, and NkB. Production of GnRH and gonadotropins along the hypothalamus-pituitary-gonadal axis are inhibited by GnIH and stimulated by QRFPs [47,48], while the tachykinin family hormone $\mathrm{NkB}$ acts in a group of hypothalamus neurons together with kisspeptin and dynorphin A in the generation of cyclic GnRH pulses [49]. The ancestral cnidarian-bilaterian GPCR for MIHR and the receptors to all these vertebrate hormones may thus already have had a role in regulating gamete production and/or release. In this case, vertebrate GPCRs in the hypothalamus and the pituitary, rather than those in gonad follicle cells or gametes, would have retained the trace of this ancestor. Likewise, protostome members of the MIHR GPCR group regulate sexual reproduction indirectly from sites far from the gonad. The planarian neuropeptide Y NPY-8 regulates gametogenesis through its GPCR expressed in central nervous system neuroendocrine hormone cells [50], while nematode luqin peptides produced by pharyngeal neurons regulate egg laying via serotonergic RIH interneurons [51].

\section{An ancient regulatory system linking reproduction and nutrition?}

It is striking that many bilaterian neuropeptide GPCRs closely related to Clytia MIHR are known for roles in regulating feeding and nutritional balance. In mammals, these include GPR83/PEN [52] as well as QRFP receptors and neuropeptide Y receptors, which provide important links between metabolic state and reproductive regulation [53-55], in conjunction with GnIH signalling [56]. Related hormone receptor families from protostomes are also known for regulating feeding, including those for Drosophila leucokinin [57] and luqins in arthropods (RYamides) and nematodes [51,58]. It is thus tempting to propose that the ancestral GPCR of the Clytia MIHR and these bilaterian hormone receptor families was involved in integrating sexual reproduction with nutritional status. It should be noted, however, that bilaterian neuropeptide GPCRs in this superfamily also function in many other physiological 


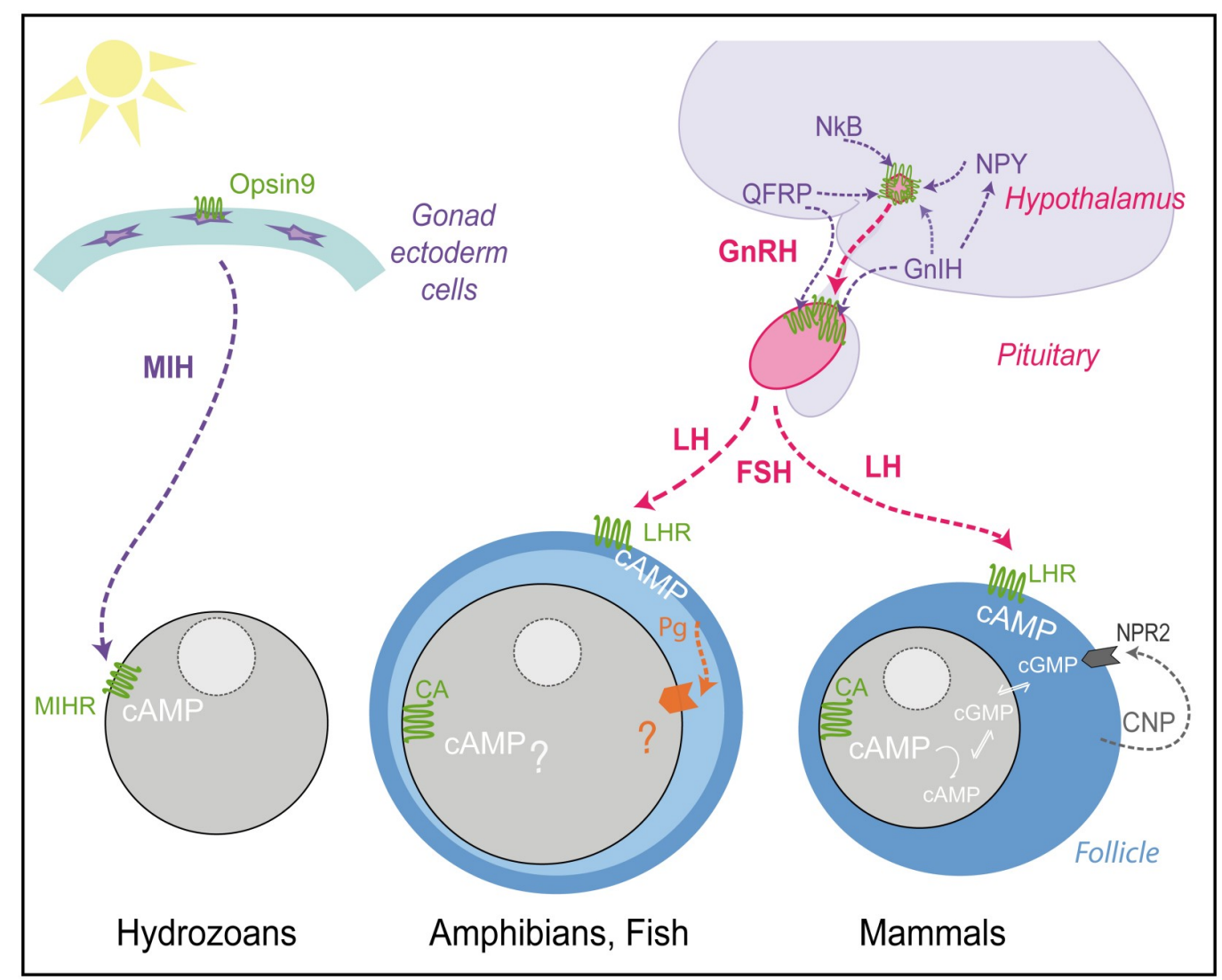

Fig 7. Schematic comparison of GPCR regulation of Clytia and vertebrate oocyte maturation. Simplified view of the tissues, hormones, and receptors involved in regulating oocyte maturation in Clytia and in fish/amphibians and mammals. For simplicity, we have not included protostome or echinoderm models. The principle peptide hormones of the reproductive hypothalamus-pituitary-gonadal axis (GnRH and LH/FSH) are in pink, and those for which the receptors group phylogenetically with Clytia MIHR in "Group A" (Fig 6) are in purple. Peptide hormones: Clytia MIH, Neuropeptide Y (NPY), GnIH, GnRH, LH, QRFP, NkB, and C-type natriuretic peptide (CNP). All their receptors, except the guanylyl cyclase natriuretic peptide receptor 2 (NPR2) activated by CNP, are GPCRs (green). Constitutively active (CA) GPCRs in vertebrate oocytes maintain cytoplasmic cAMP levels high prior to maturation. In mouse oocytes, a cAMP decrease upon hormone stimulation triggers maturation; however, in fish and frog oocytes the degree and role of this decrease is debated. Several types of oocytes receptor (orange) may respond to steroid hormones (Pg) in different species of amphibians and fish, but the relative importance of multiple downstream signalling pathways remains to be clarified $[1,43,44,45,46]$. See text for discussion. CNP, C-type natriuretic peptide; FSH, follicle-stimulating hormone; GnIH, gonadotropin inhibitory hormone; GnRH, gonadotropin-releasing hormone; GPCR, G protein-coupled receptor; $\mathrm{LH}$, luteinizing hormone; LHR, lutenizing hormone receptor; $\mathrm{MIH}$, maturation-inducing hormone; MIHR, MIH receptor; $\mathrm{NkB}$, neurokinin B; QRFP, pyroglutamylated RFamide peptide.

https://doi.org/10.1371/journal.pbio.3000614.g007

processes. Conversely, many neuropeptide hormone systems involved in integrating sexual reproduction with feeding, notably including kisspeptin, involve GPCRs only distantly related to MIHR [35,37,59]. To unravel further the evolutionary history of hormonal regulation of gamete production in relation to nutrition, it will be of great interest to address the non-oocyte functions of MIHR in Clytia, and also to determine the functions of other "group A" GPCRs from Clytia and other cnidarian species.

\section{Methods}

\section{Animals}

Sexually mature jellyfish generated from laboratory maintained C. hemisphaerica polyp colonies ("Z strains") [26] were fed regularly with Artemia nauplii and cultured under light-dark 
cycles to allow daily spawning. Red Sea Salt brand artificial seawater (ASW) was used for all culture and experiments.

\section{Selection of candidate Clytia MIH receptors}

From a comprehensive Clytia reference transcriptome (86,606 contigs) derived from mixed larva, polyp, and jellyfish samples, we generated a list of predicted protein sequences from complete and incomplete ORFs using a homemade script [60]. This dataset was screened using TMHMM 2.0c to produce a list of Clytia complete protein sequences coding for 7TM proteins, including putative incomplete sequences containing 2 to 7 transmembrane domains. Scanning with Interproscan 5.22 was used to generate a list of 761 potential Clytia GPCRs with Pfam tags related to 7TMD receptors that were retained and sorted by class. CD-HIT [61] was run with 95\% identity to eliminate sequence duplicates, obtaining a final dataset of 536 Clytia GPCRs (sequences in S1 Text). Illlumina HiSeq 50-nt reads from mRNA isolated from manually dissected gonad ectoderm, endoderm, growing oocytes, and fully grown oocytes [16] and from other Clytia life cycle stages, including polyp and planula larvae [26], were mapped against all candidate GPCR sequences using Bowtie2 [62]. The counts for each contig were normalized per total reads of each sample and contig length to allow expression comparisons between genes and samples.

Presumptive GPCR sequences were separated in groups using a hierarchical pipeline based on the correlation of their expressions (gplots package in R). Z-scores were obtained after standardization of the counts in the different sequenced samples for each GPCR candidate (S5 Data) and plotted in a heat map using R (S1 Fig). For clustering, a previous collection of GPCRs [25] was complemented with several bilaterian class C GPCRs retrieved from UniProtKB and all putative Clytia GPCRs. Clustering analysis was performed using CLANS2 [63] with a BLOSUM62 matrix and a $p$-value cutoff of 1e-30. Based on this information, Pfam signatures, reciprocal BLASTs, and high expression level in oocytes, a subset of 16 top candidates was manually selected (sequences and accession numbers in S2 Text).

\section{Candidate receptor cloning}

The selected Clytia GPCRs were cloned from gonad-extracted cDNA into pcDNA3.1(+) (Thermo Fisher Scientific, Waltham, MA) using the Gibson Assembly Cloning Kit (New England Biolabs) [64]. pcDNA3.1(+) vector was linearized with BamHI and NotI restriction enzymes. Primers were designed using the Gibson Cloning option in Geneious v8. Forward primers consisted of the overhang left after BamHI vector linearization followed by the Kozak consensus sequence (CGCCACC), a start codon (ATG), and a sequence corresponding to the target sequence. Reverse primers consisted of the overhang left after NotI vector linearization followed by a STOP codon, and a reverse complementary sequence to the target sequence. The primers for all cloned GPCRs are listed in S1 Table. Polymerase chain reaction was performed using Phusion polymerase (New England Biolabs). Cloned GPCRs were sequenced using primers for T7: TAATACGACTCACTATAGGG and BGHrev: TAGAAGGCACAGTCGA GG.

\section{Receptor deorphanization}

Cell culture GPCR ligand response assays were performed as described [28]. Briefly, CHO-K1 cells were cultured in Ham's F12 Nut Mix medium (Thermo Fisher Scientific) with 10\% foetal bovine serum. Cells were seeded in 96-well plates at approximately 10,000 cells/well and transfected the following day with pcDNA3.1(+) plasmids encoding each of the 16 candidate Clytia GPCRs (S2 Text), the promiscuous $\mathrm{G} \alpha-16$ protein [65], and a reporter construct GFP- 
apoaequorin [66] (60 ng each) using the transfection reagent TurboFect (Thermo Fisher Scientific). After 2 days of expression, the medium was removed and replaced with Hank's balanced salt solution (HBSS) supplemented with $1.8 \mathrm{mM} \mathrm{Ca2+,} 10 \mathrm{mM}$ glucose, and $1 \mathrm{mM}$ coelenterazine h (Promega, Madison, WI). After incubation at $37^{\circ} \mathrm{C}$ for 2 hours, cells were tested by adding synthetic peptides (GenScript) in HBSS supplemented with $1.8 \mathrm{mM} \mathrm{Ca}^{+}$and $10 \mathrm{mM}$ glucose. A list of all synthetic peptides used is provided in S2 Table. Luminescence was recorded for 45 seconds in a plate reader (BioTek Synergy Mx or Synergy H4; BioTek, Winooski, VT). Data were integrated over the 45 -second measurement period and recorded as technical triplicates in each case. Data were normalized using the response of Platynereis FLamide receptor to $1 \mu \mathrm{M}$ AKYFL-NH2 [28]. Dose-response curves were obtained using concentrations between $0.01 \mathrm{nM}$ and $100 \mu \mathrm{M}$ for each peptide. Data for dose-response curves were recorded in triplicate for each concentration and the experiment was repeated independently 3 times. Dose-response curves were fitted with a four-parameter curve using Prism 6 (GraphPad, La Jolla, CA) and were normalized to the calculated upper plateau values (100\% activation).

\section{Generation of CRISPR-Cas9 mutant Clytia polyp colonies}

Following our established protocol [67], MIHR small guide RNA (sgRNA) was assembled by hybridizing crRNA (CRISPR RNA) and tracrRNA synthesized at IDT (Integrated DNA Technologies, Coralville, IA), obtaining a final concentration of $50 \mu \mathrm{M}$. sgRNA was kept at $-80{ }^{\circ} \mathrm{C}$ until use. The crRNA MIHR sequence is shown in S3 Table. We avoided off-target matches by scanning the Clytia genome assembly at http://crispor.tefor.net. Purified Cas9 protein in Cas9 buffer (10 mM Hepes, $150 \mathrm{mM} \mathrm{KCl}$ ) provided by J-P Concordet (MNHN Paris) was diluted to $10 \mu \mathrm{M}$. sgRNA was added to Cas9 protein in excess (approximately 2:1) prior to injection and incubated for 10 minutes at room temperature. The final Cas 9 concentration was adjusted to $4 \mu \mathrm{M}$ and for sgRNA to $10 \mu \mathrm{M}$. The mixture was centrifuged at $14,000 \mathrm{rpm}$ for 10 minutes at room temperature before injection ( $2 \%-3 \%$ of egg volume) into unfertilized eggs within 1 hour after spawning, prior to fertilization.

Injected embryos were cultured for 3 days in Millipore-filtered seawater (MFSW) at 18$20{ }^{\circ} \mathrm{C}$. Metamorphosis of planula larvae into polyps was induced about 72 hours after fertilization by placing larvae (20-80/slide) on $75 \times 50 \mathrm{~mm}$ glass slides in drops of 3-4 mL MFSW containing $1 \mu \mathrm{g} / \mathrm{mL}$ synthetic metamorphosis peptide (GNPPGLW-amide), followed by overnight incubation. Slides with fixed primary polyps were transferred to small aquariums kept at $24{ }^{\circ} \mathrm{C}$, a temperature which favors the establishment of female colonies [68]. Primary polyps and young polyp colonies were fed twice a day with smashed Artemia nauplii until they were grown enough to be fed with swimming nauplii. Following colony vegetative expansion, a single well-growing colony on each slide was maintained as a founder. After several weeks of growth, polyp colonies were genotyped to assess mutation efficiency and mosaicism, and medusae were collected from the most strongly mutant colony (MIHR KO) for further experimentation.

\section{Genotyping}

Genomic DNA from Clytia polyps was purified using DNeasy blood/tissue extraction kit (Qiagen). The MIHR target site was amplified by PCR using Phusion DNA polymerase. Primers used for genotyping are listed in S3 Table. PCR products were sequenced and mutation efficiency was assessed using TIDE analyses [69]. In cases in which Agarose gel analysis of the PCR product revealed large insertions or deletions, this was cloned into pGEM-T Easy vector and clones randomly selected for individual sequencing. 


\section{Gonad spawning assays}

Sexually mature MIHR mutant medusae from colonies n5-13 and n5-23 and wild-type medusae were cultured on the same day-night cycle. Individual gonads were dissected in the evening after afternoon spawning. To test the light response, one group of each was transferred to $100 \mu \mathrm{L}$ MFSW in wells of 96-well plastic plates, covered overnight, and reexposed to white light the following day. To test responses to MIH and CAMP, other groups of dissected gonads were cultured overnight in constant light, then transferred to 96-well plastic plates for two hours. MIH was added to wells as an equal volume of $200 \mathrm{nM} \mathrm{WPRPa}$ mide (GenScript) stock in MFSW was added to give a final concentration of $100 \mathrm{nM}$. Alternatively, a stock of $20 \mathrm{mM}$ bromo adenosine $3^{\prime}, 5^{\prime}$ cyclic monophosphate (Br-cAMP-Fluka; Sigma Aldrich) in distilled water was added to give a final concentration of $4 \mathrm{mM}$. Gonads were washed after 5 minutes incubation in Br-cAMP. Oocyte maturation was scored after 30 minutes as germinal vesicle breakdown (GVBD), i.e., visible dissolution of the oocyte nuclear membrane upon entry into $M$ phase, which in all cases was followed by spawning about 1 hour later. Gonads that showed premature maturation or spawning due to manipulation stress were excluded from analysis.

\section{Oocyte maturation assays}

Fully grown oocytes were isolated manually from dissected gonads of wild-type and MIHR KO mutant jellyfish prepared as above. Maturation assays were performed in wells of 96 -well plates or small plastic petri dishes lined with $2 \%$ agarose in MFSW. Spontaneous maturation occurs at a low frequency in control oocytes. To test MIH-induced maturation, $10 \mu \mathrm{L}$ WPRPamide from $1 \mu \mathrm{M}$ solution in MFSW was added to a final concentration of $100 \mathrm{nM}$. In some experiments, Br-cAMP from a $20 \mathrm{mM}$ stock in $\mathrm{H}_{2} \mathrm{O}$ was used at a final concentration of $4 \mathrm{mM}$. GVBD was scored at 30 minutes, every 5 minutes, depending on experiments.

Antibody injection into isolated oocytes was performed using Nanoject or Narishige compressed air microinjection systems [70,71]. Solutions were centrifuged at $14,000 \mathrm{rpm}$ at $4{ }^{\circ} \mathrm{C}$ for 5 minutes before use, and approximately $2 \%$ oocyte volume injected. An inhibitory anti$\mathrm{G \alpha}_{\mathrm{S}}$ antibody [33] was concentrated to $14 \mathrm{mg} / \mathrm{mL}$ in PBS by three passages through an ULTRAFREE spin column (Millipore- UFV5BQK25). A purified anti-GST antibody (Sigma $67781)$ at $8.3 \mathrm{mg} / \mathrm{mL}$ in PBS was used as a control.

\section{GPCR molecular phylogeny}

Clustering analysis was performed using CLANS2 [63] with a BLOSUM62 matrix and a $p$ value cutoff of 1e-40 or 1e-50. Sequences were retrieved from NCBI (Homo and Nematostella) and from [28] for the deorphanized Platynereis GPCRs. Nematostella GPCRs were identified using HMMER [72]. Identifiers for the sequences used are given in S3 and S4 Texts. Multiple alignments were generated using Muscle [73] with default parameters. Positions containing more than $80 \%$ gaps were excluded from the alignment, provided in S5 Text. Phylogenetic analyses were performed using RaxML v8.2.9 [74] and the model PROTGAMMAGTR with Bootstrap support calculated from 500 replicates. The resulting tree file was visualized with FigTree (http://tree.bio.ed.ac.uk/software/figtree/).

\section{In situ hybridization}

A urea-based protocol for in situ hybridization was used as previously $[15,16,32]$. 


\section{Immunofluorescence}

For co-staining of neuropeptides and tyrosinated tubulin, dissected Clytia gonads and whole medusae were fixed overnight at $18{ }^{\circ} \mathrm{C}$ in HEM buffer (0.1 M HEPES, pH 6.9; 50 mM EGTA; $10 \mathrm{mM} \mathrm{MgSO}_{4}$ ) containing 3.7\% formaldehyde, then washed five times in PBS containing $0.1 \%$ Tween 20 (PBS-T). Treatment on ice with 50\% methanol/PBS-T then $100 \%$ methanol plus storage in methanol at $-20{ }^{\circ} \mathrm{C}$ improved visualization of microtubules in neural cells. Samples were rehydrated, washed several times in PBS-0.02\% Triton X-100, then one time in PBS-0.2\% Triton X-100 for 20 minutes, and again several times in PBS-0.02\% Triton X-100. After overnight incubation at $4{ }^{\circ} \mathrm{C}$ in PBS with $3 \%$ BSA, they were incubated in a rabbit antiPRPa antibody [15] and a rat monoclonal anti-Tyr tubulin (YL1/2, Thermo Fisher Scientific) in PBS/BSA at room temperature for 2 hours. After washes, the specimens were incubated with secondary antibodies (rhodamine goat anti-rabbit and Cy5 donkey anti-rat IgG; Jackson ImmunoResearch, West Grove, PA) overnight in PBS at $4{ }^{\circ} \mathrm{C}$, and nuclei were stained using Hoechst dye 33258. Images were acquired using a Leica SP8 confocal microscope and maximum intensity projections of $\mathrm{z}$-stacks prepared using ImageJ software. Phalloidin staining of fixed, non-methanol-treated gonads was performed as previously [16].

\section{Statistics}

Fisher exact tests were performed at http://www.socscistatistics.com.

\section{Supporting information}

S1 Fig. Expression of Clytia GPCRs across tissues and life cycle stages. Heat map representing the expression of putative Clytia GPCRs in the different samples studied derived from RNA-seq data (see Methods), in which sequences are clustered according to similarity of their profiles across tissues and stages. Z-score values are color-coded to reflect significantly higher (dark blue) or lower (pale green) than average values - see z-value distribution in inset. Three main profile groups showed expression enriched in the oocytes (colored boxes). Numerical data available in S5 Data. EG, early gastrula; FGOo, fully grown oocyte; GEC, gonad ectoderm; GEN, gonad endoderm; GO, gonozooid; GPCR, G protein-coupled receptor; GrOo, growing oocyte; PH, polyp head; P2/3, 2/3-day old planula larva; RNA-seq, RNA sequencing; R1/R2, Biological Replicate1/2 for Illumina sequencing; St, stolon.

(JPG)

S2 Fig. Phylogenetic tree file corresponding to Fig 6D, including identifiers for all sequences. Maximum likelihood analyses were performed using RaxML v8.2.9, and the model PROTGAMMAGTR with Bootstrap support was calculated from 500 replicates. Species colorcoding as in Fig 6D: Platynereis, green; Human, blue, Clytia, orange; Nematostella, black. (JPG)

S1 Text. FASTA file of Clytia candidate GPCR sequences. GPCR, G protein-coupled receptor.

(DOC)

S2 Text. FASTA file of the cloned Clytia candidate MIHR sequences, with their GenBank accession numbers in parentheses. MIHR, MIH receptor.

(DOC)

S3 Text. Sequences used for CLANS2 clustering in Fig 6A and 6B. (DOC) 
S4 Text. Sequences used for CLANS2 clustering in Fig 6C. (DOC)

S5 Text. FASTA file of the GPCR alignment used for phylogenetic analyses shown in Fig 6D. GPCR, G protein-coupled receptor.

(DOC)

S1 Table. Details of PCR primers for GPCR cloning. GPCR, G protein-coupled receptor. (XLSX)

S2 Table. List of peptides used for GPCR deorphanization. GPCR, G protein-coupled receptor.

(XLSX)

S3 Table. List of crRNA, CRISPR, and PCR primers for mutant genotyping. crRNA, CRISPR RNA.

(XLSX)

S1 Data. Numerical data corresponding to Fig 1B. Raw luminescence values obtained in triplicate for each of the neuropeptide combinations tested against the MIHR in the deorphanization assay are provided. In the right-hand table, the raw luminescence values obtained in quadruple for the positive and negative controls are provided. In the lower table, means and standard errors of the mean of the luminescence values obtained for each neuropeptide combination and controls are also shown, as well as the values normalized to the positive control, which were used to prepare the graph shown in Fig 1B. MIHR, MIH receptor.

(XLSX)

S2 Data. Numerical data corresponding to Fig 1C. The first three tabs show statistical values obtained using Prism 6 software (GraphPad, La Jolla, CA) from the raw luminescence values for 3 independent dose-response experiments. The first dataset (first tab) was used to create the graph shown in Fig 1C. The raw luminescence values are shown, as well as the values normalized with respect to the maximum. The 4 th tab shows the different $\mathrm{EC}_{50}$ values calculated by Prism 6 software for each MIH neuropeptide from each of the 3 biological replicates, as well as the means shown in Fig 1C. MIH, maturation-inducing hormone.

(XLSX)

S3 Data. Numerical data corresponding to Fig 4A and 4C. The first tab collects all the raw data from 3 independent gonad spawning assays. The means and standard deviations were used to prepare the graph shown in Fig 4A. Information corresponding to the Fisher exact tests is also shown. The second tab shows the raw data from 3 independent oocyte maturation assays. The means and standard deviations were used to prepare the graph in Fig 4C. Information corresponding to the Fisher exact tests is also shown.

(XLSX)

S4 Data. Numerical data corresponding to Fig 5A. Data from 5 experiments are provided in the first tab. In experiments 1 and 2, oocytes were injected with either anti-Go $\alpha_{s}$ or PBS. In experiments 3-5, oocytes were injected with either anti-G $\alpha_{s}$ or PBS or anti-GST. Injections were performed with a Narishige setup except for experiment 5, which used a nanoject apparatus and delivered less regular injections. Experiment 4 is illustrated in Fig 5A. The number of oocytes with intact GVs at the end of each successive treatment is indicated. The full details of these last three experiments are provided in tabs 2-4, including the timing and doses of MIH treatments, and the GV-intact oocyte counts at successive times. GST, Glutathione-S-Transferase; GV, Germinal Vesicle; MIH, maturation- 
inducing hormone.

(XLSX)

S5 Data. Numerical data corresponding to S1 Fig. Normalized counts in the different sequenced samples for each GPCR candidate. GPCR, G protein-coupled receptor.

(XLSX)

\section{Acknowledgments}

We thank our LBDV colleagues Philippe Dru for Bioinformatics support, Maeva Goulais for assistance with immunofluorescence, and Céline Hebras for antibody injections. Thanks also to J.-P. Concordet (MNHN Paris) for generously providing Cas9 protein, Noriyo Takeda (Hiroshima University) for the anti-PRPamide antibody, and Laurinda Jaffe (University of Connecticut Health Centre) for the anti-G $\alpha_{S}$ antibody. For animal care and microscopy, we thank of the Service Aquariologie (especially Alexandre Jan) and the Villefranche-sur-mer Imaging platform of the Institut de la Mer de Villefranche (IMEV)/EMBRC-France.

\section{Author Contributions}

Conceptualization: Evelyn Houliston.

Data curation: Pascal Lapébie.

Formal analysis: Pascal Lapébie, Lucas Leclère.

Funding acquisition: Gáspár Jékely, Evelyn Houliston.

Investigation: Gonzalo Quiroga Artigas, Philipp Bauknecht, Julie Uveira, Sandra Chevalier.

Project administration: Evelyn Houliston.

Supervision: Gáspár Jékely, Tsuyoshi Momose, Evelyn Houliston.

Writing - original draft: Gonzalo Quiroga Artigas, Evelyn Houliston.

Writing - review \& editing: Gonzalo Quiroga Artigas, Pascal Lapébie, Lucas Leclère, Gáspár Jékely, Tsuyoshi Momose, Evelyn Houliston.

\section{References}

1. Voronina E, Wessel GM. The regulation of oocyte maturation. Curr Top Dev Biol. 2003; 58: 53-110. https://doi.org/10.1016/s0070-2153(03)58003-6 PMID: 14711013

2. Verlhac M-H, Terret M-E. Oocyte Maturation and Development. F1000Res. 2016; 5. https://doi.org/10. 12688/f1000research.7892.1 PMID: 26998245

3. Amiel A, Leclère L, Robert L, Chevalier S, Houliston E. Conserved functions for Mos in eumetazoan oocyte maturation revealed by studies in a cnidarian. Curr Biol. 2009; 19: 305-311. https://doi.org/10. 1016/j.cub.2008.12.054 PMID: 19230670

4. Von Stetina JR, Orr-Weaver TL. Developmental control of oocyte maturation and egg activation in metazoan models. Cold Spring Harb Perspect Biol. 2011; 3: a005553. https://doi.org/10.1101/ cshperspect.a005553 PMID: 21709181

5. Hartenstein V. The neuroendocrine system of invertebrates: a developmental and evolutionary perspective. J Endocrinol. 2006; 190: 555-570. https://doi.org/10.1677/joe.1.06964 PMID: 17003257

6. Deguchi R, Takeda N, Stricker SA. Comparative biology of cAMP-induced germinal vesicle breakdown in marine invertebrate oocytes. Mol Reprod Dev. 2011; 78: 708-725. https://doi.org/10.1002/mrd. 21346 PMID: 21774023

7. Le Tissier P, Campos P, Lafont C, Romanò N, Hodson DJ, Mollard P. An updated view of hypothalamic-vascular-pituitary unit function and plasticity. Nat Rev Endocrinol. 2017; 13: 257-267. https://doi. org/10.1038/nrendo.2016.193 PMID: 27934864 
8. Kristiansen K. Molecular mechanisms of ligand binding, signaling, and regulation within the superfamily of G-protein-coupled receptors: molecular modeling and mutagenesis approaches to receptor structure and function. Pharmacol Ther. 2004; 103: 21-80. https://doi.org/10.1016/j.pharmthera.2004.05.002 PMID: 15251227

9. Neves SR, Ram PT, lyengar R. G protein pathways. Science. 2002; 296: 1636-1639. https://doi.org/ 10.1126/science.1071550 PMID: 12040175

10. Oldham WM, Hamm HE. Heterotrimeric G protein activation by G-protein-coupled receptors. Nat Rev Mol Cell Biol. 2008; 9: 60-71. https://doi.org/10.1038/nrm2299 PMID: 18043707

11. Chakravorty $D$, Assmann SM. G protein subunit phosphorylation as a regulatory mechanism in heterotrimeric G protein signaling in mammals, yeast, and plants. Biochem J. 2018; 475: 3331-3357. https:// doi.org/10.1042/BCJ20160819 PMID: 30413679

12. Kalinowski RR, Berlot CH, Jones TLZ, Ross LF, Jaffe LA, Mehlmann LM. Maintenance of meiotic prophase arrest in vertebrate oocytes by a Gs protein-mediated pathway. Dev Biol. 2004; 267: 1-13. https://doi.org/10.1016/j.ydbio.2003.11.011 PMID: 14975713

13. Freudzon L, Norris RP, Hand AR, Tanaka S, Saeki Y, Jones TLZ, et al. Regulation of meiotic prophase arrest in mouse oocytes by GPR3, a constitutive activator of the Gs G protein. J Cell Biol. 2005; 171: 255-265. https://doi.org/10.1083/jcb.200506194 PMID: 16247026

14. Nader N, Dib M, Daalis A, Kulkarni RP, Machaca K. Role for endocytosis of a constitutively active GPCR (GPR185) in releasing vertebrate oocyte meiotic arrest. Dev Biol. 2014; 395: 355-366. https:// doi.org/10.1016/j.ydbio.2014.08.036 PMID: 25220151

15. Takeda N, Kon $Y$, Quiroga Artigas G, Lapébie $P$, Barreau C, Koizumi O, et al. Identification of jellyfish neuropeptides that act directly as oocyte maturation-inducing hormones. Development. 2018; 145. https://doi.org/10.1242/dev.156786 PMID: 29358214

16. Quiroga Artigas G, Lapébie $P$, Leclère L, Takeda N, Deguchi R, Jékely G, et al. A gonad-expressed opsin mediates light-induced spawning in the jellyfish. Elife. 2018; 7. https://doi.org/10.7554/eLife. 29555 PMID: 29303477

17. Takahashi T, Takeda N. Insight into the Molecular and Functional Diversity of Cnidarian Neuropeptides. International Journal of Molecular Sciences. 2015. pp. 2610-2625. https://doi.org/10.3390/ ijms16022610 PMID: 25625515

18. Bosch TCG, Klimovich A, Domazet-Lošo T, Gründer S, Holstein TW, Jékely G, et al. Back to the Basics: Cnidarians Start to Fire. Trends Neurosci. 2017; 40: 92-105. https://doi.org/10.1016/j.tins.2016.11.005 PMID: 28041633

19. Grimmelikhuijzen CJP, Hauser F. Mini-review: the evolution of neuropeptide signaling. Regul Pept. 2012; 177 Suppl: S6-9.

20. Elphick MR, Mirabeau O, Larhammar D. Evolution of neuropeptide signalling systems. J Exp Biol. 2018; 221. https://doi.org/10.1242/jeb.151092 PMID: 29440283

21. Freeman G, Ridgway EB. The role of cAMP in oocyte maturation and the role of the germinal vesicle contents in mediating maturation and subsequent developmental events in hydrozoans. Rouxs Arch Dev Biol. 1988; 197: 197-211. https://doi.org/10.1007/BF02439427 PMID: 28305628

22. Takeda N, Kyozuka K, Deguchi R. Increase in intracellular cAMP is a prerequisite signal for initiation of physiological oocyte meiotic maturation in the hydrozoan Cytaeis uchidae. Dev Biol. 2006; 298: 248258. https://doi.org/10.1016/j.ydbio.2006.06.034 PMID: 16884710

23. Jékely G, Melzer S, Beets I, Kadow ICG, Koene J, Haddad S, et al. The long and the short of it-a perspective on peptidergic regulation of circuits and behaviour. J Exp Biol. 2018; 221. https://doi.org/10. 1242/jeb.166710 PMID: 29439060

24. Audet M, Bouvier M. Restructuring G-protein- coupled receptor activation. Cell. 2012; 151: 14-23. https://doi.org/10.1016/j.cell.2012.09.003 PMID: 23021212

25. Jékely G. Global view of the evolution and diversity of metazoan neuropeptide signaling. Proc Natl Acad Sci U S A. 2013; 110: 8702-8707. https://doi.org/10.1073/pnas.1221833110 PMID: 23637342

26. Leclère L, Horin $\mathrm{C}$, Chevalier $\mathrm{S}$, Lapébie $\mathrm{P}$, Dru $\mathrm{P}$, Peron $\mathrm{S}$, et al. The genome of the jellyfish Clytia hemisphaerica and the evolution of the cnidarian life-cycle. Nat Ecol Evol. 2019; 3: 801-810. https://doi. org/10.1038/s41559-019-0833-2 PMID: 30858591

27. Tunaru S, Lättig J, Kero J, Krause G, Offermanns S. Characterization of Determinants of Ligand Binding to the Nicotinic Acid Receptor GPR109A (HM74A/PUMA-G). Molecular Pharmacology. 2005. pp. 1271-1280. https://doi.org/10.1124/mol.105.015750 PMID: 16099840

28. Bauknecht $P$, Jékely $G$. Large-Scale Combinatorial Deorphanization of Platynereis Neuropeptide GPCRs. Cell Rep. 2015; 12: 684-693. https://doi.org/10.1016/j.celrep.2015.06.052 PMID: 26190115 
29. Nielsen SKD, Koch TL, Hauser F, Garm A, Grimmelikhuijzen CJP. De novo transcriptome assembly of the cubomedusa Tripedalia cystophora, including the analysis of a set of genes involved in peptidergic neurotransmission. BMC Genomics. 2019; 20: 175. https://doi.org/10.1186/s12864-019-5514-7 PMID: 30836949

30. Hayakawa E, Watanabe H, Menschaert G, Holstein TW, Baggerman G, Schoofs L. A combined strategy of neuropeptide prediction and tandem mass spectrometry identifies evolutionarily conserved ancient neuropeptides in the sea anemone Nematostella vectensis. PLoS ONE. 2019; 14: e0215185. https://doi.org/10.1371/journal.pone.0215185 PMID: 31545805

31. Condamine T, Jager M, Leclère L, Blugeon C, Lemoine S, Copley RR, et al. Molecular characterisation of a cellular conveyor belt in Clytia medusae. Dev Biol. 2019; https://doi.org/10.1016/j.ydbio.2019.09. 001 PMID: 31509769

32. Sinigaglia $C$, Thiel $D$, Hejnol $A$, Houliston $E$, Leclère L. A safer, urea-based in situ hybridization method improves detection of gene expression in diverse animal species. Dev Biol. 2018; 434: 15-23. https:// doi.org/10.1016/j.ydbio.2017.11.015 PMID: 29197505

33. Gallo CJ, Hand AR, Jones TL, Jaffe LA. Stimulation of Xenopus oocyte maturation by inhibition of the G-protein alpha S subunit, a component of the plasma membrane and yolk platelet membranes. J Cell Biol. 1995; 130: 275-284. https://doi.org/10.1083/jcb.130.2.275 PMID: 7615631

34. Mehlmann LM, Jones TLZ, Jaffe LA. Meiotic arrest in the mouse follicle maintained by a Gs protein in the oocyte. Science. 2002; 297: 1343-1345. https://doi.org/10.1126/science.1073978 PMID: 12193786

35. Mirabeau O, Joly J-S. Molecular evolution of peptidergic signaling systems in bilaterians. Proc Natl Acad Sci U S A. 2013; 110: E2028-37. https://doi.org/10.1073/pnas.1219956110 PMID: 23671109

36. Zandawala M, Moghul I, Yañez Guerra LA, Delroisse J, Abylkassimova N, Hugall AF, et al. Discovery of novel representatives of bilaterian neuropeptide families and reconstruction of neuropeptide precursor evolution in ophiuroid echinoderms. Open Biol. 2017; 7. https://doi.org/10.1098/rsob.170129 PMID: 28878039

37. Thiel D, Franz-Wachtel M, Aguilera F, Hejnol A. Xenacoelomorph Neuropeptidomes Reveal a Major Expansion of Neuropeptide Systems during Early Bilaterian Evolution. Molecular Biology and Evolution. 2018. pp. 2528-2543. https://doi.org/10.1093/molbev/msy160

38. Anctil M. Chemical transmission in the sea anemone Nematostella vectensis: A genomic perspective. Comp Biochem Physiol Part D Genomics Proteomics. 2009; 4: 268-289. https://doi.org/10.1016/j.cbd. 2009.07.001 PMID: 20403752

39. Haccard O, Jessus C. Oocyte Maturation, Mos and Cyclins-A Matter of Synthesis: Two Functionally Redundant Ways to Induce Meiotic Maturation. Cell Cycle. 2006. pp. 1152-1159. https://doi.org/10. 4161/cc.5.11.2800 PMID: 16760654

40. Nagahama Y, Yamashita M. Regulation of oocyte maturation in fish. Dev Growth Differ. 2008; 50 Suppl 1: S195-219.

41. Kishimoto T. MPF-based meiotic cell cycle control: Half a century of lessons from starfish oocytes. Proceedings of the Japan Academy, Series B. 2018. pp. 180-203. https://doi.org/10.2183/pjab.94.013 PMID: 29643273

42. Jaffe LA, Egbert JR. Regulation of Mammalian Oocyte Meiosis by Intercellular Communication Within the Ovarian Follicle. Annual Review of Physiology. 2017. pp. 237-260. https://doi.org/10.1146/annurevphysiol-022516-034102 PMID: 27860834

43. Lutz LB, Kim B, Jahani D, Hammes SR. G protein beta gamma subunits inhibit nongenomic progesterone-induced signaling and maturation in Xenopus laevis oocytes. Evidence for a release of inhibition mechanism for cell cycle progression. J Biol Chem. 2000; 275: 41512-41520. https://doi.org/10.1074/ jbc.M006757200 PMID: 11018039

44. Zhu $Y$, Rice $C D$, Pang $Y$, Pace $M$, Thomas $P$. Cloning, expression, and characterization of a membrane progestin receptor and evidence it is an intermediary in meiotic maturation of fish oocytes. Proc Natl Acad Sci U S A. 2003; 100: 2231-2236. https://doi.org/10.1073/pnas.0336132100 PMID: 12574519

45. Ben-Yehoshua LJ, Lewellyn AL, Thomas P, Maller JL. The Role of Xenopus Membrane Progesterone Receptor $\beta$ in Mediating the Effect of Progesterone on Oocyte Maturation. Molecular Endocrinology. 2007. pp. 664-673. https://doi.org/10.1210/me.2006-0256 PMID: 17185392

46. Nader N, Courjaret R, Dib M, Kulkarni RP, Machaca K. Release from Xenopus oocyte prophase I meiotic arrest is independent of a decrease in cAMP levels or PKA activity. Development. 2016; 143: 19261936. https://doi.org/10.1242/dev.136168 PMID: 27122173

47. Patel SR, Murphy KG, Thompson EL, Patterson M, Curtis AE, Ghatei MA, et al. Pyroglutamylated RFamide Peptide 43 Stimulates the Hypothalamic-Pituitary-Gonadal Axis via Gonadotropin-Releasing Hormone in Rats. Endocrinology. 2008. pp. 4747-4754. https://doi.org/10.1210/en.2007-1562 PMID: 18535111

48. Tsutsui K, Bentley GE, Kriegsfeld LJ, Osugi T, Seong JY, Vaudry H. Discovery and Evolutionary History of GnIH and Kisspeptin: New Key Neuropeptides Controlling Reproduction. Journal of Neuroendocrinology. 2010. p. no-no. https://doi.org/10.1111/j.1365-2826.2010.02018.x PMID: 20456604 
49. Hu G, Lin C, He M, Wong AOL. Neurokinin B and reproductive functions: "KNDy neuron" model in mammals and the emerging story in fish. Gen Comp Endocrinol. 2014; 208: 94-108. https://doi.org/10.1016/ j.ygcen.2014.08.009 PMID: 25172151

50. Saberi A, Jamal A, Beets I, Schoofs L, Newmark PA. GPCRs Direct Germline Development and Somatic Gonad Function in Planarians. PLoS Biol. 2016; 14: e1002457. https://doi.org/10.1371/journal. pbio.1002457 PMID: 27163480

51. Ohno H, Yoshida M, Sato T, Kato J, Miyazato M, Kojima M, et al. Luqin-like RYamide peptides regulate food-evoked responses in C. elegans. eLife 2017; 6: e28877. https://doi.org/10.7554/eLife.28877 PMID: 28847365

52. Gomes I, Bobeck EN, Margolis EB, Gupta A, Sierra S, Fakira AK, et al. Identification of GPR83 as the receptor for the neuroendocrine peptide PEN. Sci Signal. 2016; 9: ra43.

53. Chartrel N, Picot M, El Medhi M, Arabo A, Berrahmoune H, Alexandre D, et al. The Neuropeptide 26RFa (QRFP) and Its Role in the Regulation of Energy Homeostasis: A Mini-Review. Front Neurosci. 2016; 10: 549. https://doi.org/10.3389/fnins.2016.00549 PMID: 27965532

54. Navarro VM, Fernández-Fernández R, Nogueiras R, Vigo E, Tovar S, Chartrel N, et al. Novel role of 26RFa, a hypothalamic RFamide orexigenic peptide, as putative regulator of the gonadotropic axis. J Physiol. 2006; 573: 237-249. https://doi.org/10.1113/jphysiol.2006.106856 PMID: 16543265

55. Wójcik-Gładysz A, Polkowska J. Neuropeptide $Y$-a neuromodulatory link between nutrition and reproduction at the central nervous system level. Reprod Biol. 2006; 6 Suppl 2: 21-28.

56. Tsutsui K, Ubuka T. GnIH Control of Feeding and Reproductive Behaviors. Front Endocrinol. 2016; 7: 170.

57. Al-Anzi B, Armand E, Nagamei P, Olszewski M, Sapin V, Waters C, et al. The leucokinin pathway and its neurons regulate meal size in Drosophila. Curr Biol. 2010; 20: 969-978. https://doi.org/10.1016/j. cub.2010.04.039 PMID: 20493701

58. Maeda T., Nakamura Y., Shiotani H., Hojo M.K., Yoshii T., Ida T., et al. Suppressive effects of dRYamides on feeding behavior of the blowfly, Phormia regina. Zoological Lett. 2015; 1: 35. https://doi.org/ 10.1186/s40851-015-0034-z PMID: 26649188

59. Shahjahan M, Kitahashi T, Parhar IS. Central pathways integrating metabolism and reproduction in teleosts. Front Endocrinol. 2014; 5: 36.

60. Lapébie P, Ruggiero A, Barreau C, Chevalier S, Chang P, Dru P, et al. Differential responses to Wnt and PCP disruption predict expression and developmental function of conserved and novel genes in a cnidarian. PLoS Genet. 2014; 10: e1004590. https://doi.org/10.1371/journal.pgen.1004590 PMID: 25233086

61. Fu L, Niu B, Zhu Z, Wu S, Li W. CD-HIT: accelerated for clustering the next-generation sequencing data. Bioinformatics. 2012; 28: 3150-3152. https://doi.org/10.1093/bioinformatics/bts565 PMID: 23060610

62. Langmead B, Salzberg SL. Fast gapped-read alignment with Bowtie 2. Nat Methods. 2012; 9: 357-359. https://doi.org/10.1038/nmeth.1923 PMID: 22388286

63. Frickey $\mathrm{T}$, Lupas A. CLANS: a Java application for visualizing protein families based on pairwise similarity. Bioinformatics. 2004; 20: 3702-3704. https://doi.org/10.1093/bioinformatics/bth444 PMID: 15284097

64. Gibson DG, Young L, Chuang R-Y, Craig Venter J, Hutchison CA, Smith HO. Enzymatic assembly of DNA molecules up to several hundred kilobases. Nature Methods. 2009. pp. 343-345. PMID: 19363495

65. Offermanns S, Simon MI. G alpha 15 and $\mathrm{G}$ alpha 16 couple a wide variety of receptors to phospholipase C. J Biol Chem. 1995; 270: 15175-15180. https://doi.org/10.1074/jbc.270.25.15175 PMID: 7797501

66. Baubet V, Le Mouellic H, Campbell AK, Lucas-Meunier E, Fossier P, Brúlet P. Chimeric green fluorescent protein-aequorin as bioluminescent $\mathrm{Ca} 2+$ reporters at the single-cell level. Proc Natl Acad Sci U S A. 2000; 97: 7260-7265. https://doi.org/10.1073/pnas.97.13.7260 PMID: 10860991

67. Momose T, De Cian A, Shiba K, Inaba K, Giovannangeli C, Concordet J-P. High doses of CRISPR/ Cas9 ribonucleoprotein efficiently induce gene knockout with low mosaicism in the hydrozoan Clytia hemisphaerica through microhomology-mediated deletion. Sci Rep. 2018; 8: 11734. https://doi.org/10. 1038/s41598-018-30188-0 PMID: 30082705

68. Carré $\mathrm{D}$, Carré $\mathrm{C}$. Origin of germ cells, sex determination, and sex inversion in medusae of the genus Clytia (Hydrozoa, leptomedusae): the influence of temperature. J Exp Zool. 2000; 287: 233-242. https://doi.org/10.1002/1097-010x(20000801)287:3<233::aid-jez5>3.3.co;2-6 PMID: 10900443

69. Brinkman EK, Chen T, Amendola M, van Steensel B. Easy quantitative assessment of genome editing by sequence trace decomposition. Nucleic Acids Res. 2014; 42(22):e168. https://doi.org/10.1093/nar/ gku936 PMID: 25300484 
70. Momose T, Houliston E. Two oppositely localised frizzled RNAs as axis determinants in a cnidarian embryo. PLoS Biol. 2007; 5: e70. https://doi.org/10.1371/journal.pbio.0050070 PMID: 17355179

71. Yasuo H, McDougall A. Practical Guide for Ascidian Microinjection: Phallusia mammillata. Adv Exp Med Biol. 2018; 1029: 15-24. https://doi.org/10.1007/978-981-10-7545-2_3 PMID: 29542077

72. Potter SC, Luciani A, Eddy SR, Park Y, Lopez R, Finn RD. HMMER web server: 2018 update. Nucleic Acids Res. 2018; 46: W200-W204. https://doi.org/10.1093/nar/gky448 PMID: 29905871

73. Edgar RC. MUSCLE: a multiple sequence alignment method with reduced time and space complexity. BMC Bioinformatics. 2004; 5: 113. https://doi.org/10.1186/1471-2105-5-113 PMID: 15318951

74. Stamatakis A. RAxML-VI-HPC: maximum likelihood-based phylogenetic analyses with thousands of taxa and mixed models. Bioinformatics. 2006. pp. 2688-2690. https://doi.org/10.1093/bioinformatics/ btl446 PMID: 16928733 